\title{
Design, Synthesis and Cytotoxic Evaluation of $o$-Carboxamido Stilbene Analogues
}

\author{
Mohamad Nurul Azmi ${ }^{1}$, Mohd Fadzli Md Din ${ }^{1}$, Chin Hui Kee ${ }^{1}$, Munirah Suhaimi ${ }^{1}$, \\ Ang Kheng Ping ${ }^{1}$, Kartini Ahmad ${ }^{2}$, Mohd Azlan Nafiah ${ }^{2}$, Noel F. Thomas ${ }^{1}$, \\ Khalit Mohamad ${ }^{3}$, Leong Kok Hoong ${ }^{3}$ and Khalijah Awang ${ }^{1, *}$ \\ 1 Department of Chemistry, Faculty of Science, University of Malaya, Kuala Lumpur 50603, \\ Malaysia; E-Mails: Mohamad.azmi@siswa.um.edu.my (M.N.A.); fadzli_md@yahoo.com (M.F.D.); \\ chkee@um.edu.my (C.H.K.); munirah_oni@siswa.um.edu.my (M.S.); \\ akping_1@hotmail.com (A.K.P.); noelfthomas@um.edu.my (N.F.T.) \\ 2 Department of Chemistry, Faculty of Science and Mathematics, Sultan Azlan Shah Campus, \\ University Pendidikan Sultan Idris, Proton City 35950, Perak Darul Ridzuan, Malaysia; \\ E-Mails: kartini@ fmst.upsi.edu.my (K.A.); azlan@fmst.upsi.edu.my (M.A.N.) \\ 3 Department of Pharmacy, Faculty of Medicine, University of Malaya, 50603 Kuala Lumpur 50603, \\ Malaysia; E-Mails: khalitmohamad@um.edu.my (K.M.); leongkh@um.edu.my (L.K.H.) \\ * Author to whom correspondence should be addressed; E-Mail: khalijah@um.edu.my; \\ Tel.: +603-7967-4064; Fax: +603-7967-4193.
}

Received: 15 July 2013; in revised form: 13 September 2013 / Accepted: 17 September 2013 / Published: 27 November 2013

\begin{abstract}
Resveratrol, a natural stilbene found in grapes and wines exhibits a wide range of pharmacological properties. Resveratrol is also known as a good chemopreventive agent for inhibiting carcinogenesis processes that target kinases, cyclooxygenases, ribonucleotide reductase and DNA polymerases. A total of 19 analogues with an amide moiety were synthesized and the cytotoxic effects of the analogues on a series of human cancer cell lines are reported. Three compounds $\mathbf{6 d}, \mathbf{6 i}$ and $\mathbf{6 n}$ showed potent cytotoxicity against prostate cancer DU-145 $\left(\mathrm{IC}_{50}=16.68 \mu \mathrm{M}\right)$, colon cancer HT-29 $\left(\mathrm{IC}_{50}=7.51 \mu \mathrm{M}\right)$ and breast cancer MCF-7 $\left(\mathrm{IC}_{50}=21.24 \mu \mathrm{M}\right)$, respectively, which are comparable with vinblastine. The resveratrol analogues were synthesized using the Heck method.
\end{abstract}

Keywords: $o$-carboxamido stilbenes; amido stilbenes; Heck protocol; cytotoxic effects 


\section{Introduction}

Resveratrol, a popular stilbenoid-type compound exerts a wide range of biological activities, such as anti-carcinogenic, antioxidant, anti-inflammatory, anti-tumor [1,2]. Resveratrol is widely found in grapes and red wine [3,4], and the amount of resveratrol in the skin of fresh grape is between 50-100 mg/g [5]. Resveratrol, a resorcinol derivative was first isolated from the Japanese plant Veratrum grandiflorum [6] and was reported as a phytoalexin produced by plants in response to pathogen attack or environmental pressure such as injuries [7]. Resveratrol is also known as a calorie restriction mimetic which is a hypothetical class of drugs that would mimic the substantial anti-aging effects caloric restrictions [8]. Resveratrol is commonly connected to the French Paradox i.e., wine-drinking population with high intake of saturated fat but with few heart related problems, which is attributed to the inhibition of LDL oxidation in human [9]. In relation to cardiovascular disease, an animal model showed that resveratrol reduces blood pressure and cardiac hypertrophy in hypertensive animals as well as protects the heart from ischemia-reperfusion injury and slows the progression of atherosclerosis [10].

The interesting and intriguing biological properties of resveratrol have attracted much attention from synthetic chemists which led to the synthesis of numerous analogues containing diverse range of functional groups. For instance, pterostilbene which is a simple analogue with two methoxyl groups on the aromatic ring have been shown to exhibit good cytotoxicity against estrogen-insensitive breast cancer (MDA-MB-231) [11]. Some naphthyl combretastatin analogues have been reported to inhibit tubulin polymerization [12]. Similar to the naphthalene moiety, stilbene coumarin analogues showed potent antiproliferative activity toward human lung carcinoma cell line (H460) [2]. By substituting the hydroxyl group in resveratrol with an aliphatic acid, positive result was seen in inhibiting cell apoptosis through Toll-like receptor 2 (TLR2) [13]. Another type of analogue, the benzenesulfonamides having a sulfonamide moiety, were tested against 60 human tumor cell lines and were notably cytotoxic toward BT-549 breast cancer and HT-29 colon cancer [14].

Previously our group has synthesized a nine $o$-carboxamido stilbene, incorporating the amide moiety and exhibiting good biological activity against a colon cell line (HT-29), liver cell line (HEP-G2), Jurkat cell and murine leukemic cell line [15-17]. In continuation of this study, we have further synthesized more analogues and all these compounds were evaluated for their cytotoxicity against 6 human cell lines; colon cancer (HT-29), estrogen-sensitive breast cancer (MCF-7), estrogen-insensitive breast cancer (MDA-MB-231), prostate cancer (DU-145), pancreatic cancer (BxPC-3) and normal pancreatic cells (hTERT-HPNE). A total of 19 o-carboxamido stilbenes were synthesized (6a-6s) containing different substituted groups linked to the amide group at ring A (Scheme 1). While at ring B, electron donating groups such as methoxy and electron withdrawing group $(\mathrm{Cl}, \mathrm{Br}$ and $\mathrm{F})$ were attached at different positions. 
Scheme 1. Chemical structures of $o$-carboxamido stilbene analogues mentioned in this study and general structure of the synthesized compounds $(\mathbf{6} \mathbf{a}-\mathbf{6 s})$.

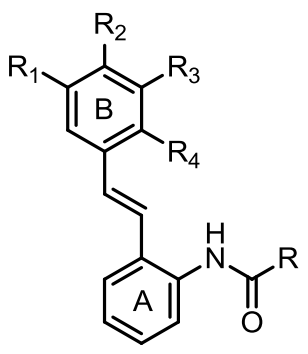

trans - stilbene (6)

\begin{tabular}{|c|c|c|c|c|c|}
\hline Compd. & $\mathbf{R}$ & $\mathbf{R}_{1}$ & $\mathbf{R}_{2}$ & $\mathbf{R}_{\mathbf{3}}$ & $\mathbf{R}_{4}$ \\
\hline $6 \mathbf{a}$ & $\mathrm{CH}_{3}$ & $\mathrm{H}$ & $\mathrm{Cl}$ & $\mathrm{H}$ & $\mathrm{H}$ \\
\hline $6 b$ & $\mathrm{CH}_{3}$ & $\mathrm{H}$ & $\mathrm{H}$ & $\mathrm{Cl}$ & $\mathrm{H}$ \\
\hline $6 c$ & $\mathrm{CH}_{3}$ & $\mathrm{H}$ & F & $\mathrm{H}$ & $\mathrm{H}$ \\
\hline $6 d$ & $\mathrm{CH}_{3}$ & $\mathrm{H}$ & $\mathrm{H}$ & $\mathrm{F}$ & $\mathrm{H}$ \\
\hline $6 e$ & $\mathrm{CH}_{3}$ & $\mathrm{H}$ & $\mathrm{Br}$ & $\mathrm{H}$ & $\mathrm{H}$ \\
\hline 6f & $\mathrm{CH}_{3}$ & $\mathrm{OCH}_{3}$ & $\mathrm{H}$ & $\mathrm{OCH}_{3}$ & $\mathrm{H}$ \\
\hline $6 \mathrm{~g}$ & & $\mathrm{H}$ & $\mathrm{H}$ & $\mathrm{H}$ & $\mathrm{OCH}_{3}$ \\
\hline $6 h$ & & $\mathrm{H}$ & $\mathrm{H}$ & $\mathrm{OCH}_{3}$ & $\mathrm{H}$ \\
\hline $6 \mathbf{i}$ & & $\mathrm{H}$ & $\mathrm{OCH}_{3}$ & $\mathrm{H}$ & $\mathrm{H}$ \\
\hline $6 j$ & & $\mathrm{OCH}_{3}$ & $\mathrm{OCH}_{3}$ & $\mathrm{H}$ & $\mathrm{H}$ \\
\hline $6 \mathbf{k}$ & & $\mathrm{OCH}_{3}$ & $\mathrm{H}$ & $\mathrm{OCH}_{3}$ & $\mathrm{H}$ \\
\hline 61 & & $\mathrm{H}$ & & $\mathrm{H}$ & $\mathrm{H}$ \\
\hline $6 m$ & & $\mathrm{H}$ & & $\mathrm{H}$ & $\mathrm{H}$ \\
\hline $6 n$ & & $\mathrm{OCH}_{3}$ & $\mathrm{OCH}_{3}$ & $\mathrm{H}$ & $\mathrm{H}$ \\
\hline 60 & & $\mathrm{H}$ & $\mathrm{OCH}_{3}$ & $\mathrm{H}$ & $\mathrm{H}$ \\
\hline $6 p$ & & $\mathrm{OCH}_{3}$ & $\mathrm{OCH}_{3}$ & $\mathrm{H}$ & $\mathrm{H}$ \\
\hline $6 q$ & & $\mathrm{OCH}_{3}$ & $\mathrm{OCH}_{3}$ & $\mathrm{H}$ & $\mathrm{H}$ \\
\hline $6 r$ & & $\mathrm{H}$ & $\mathrm{OCH}_{3}$ & $\mathrm{H}$ & $\mathrm{H}$ \\
\hline $6 s$ & & $\mathrm{OCH}_{3}$ & $\mathrm{OCH}_{3}$ & $\mathrm{H}$ & $\mathrm{H}$ \\
\hline
\end{tabular}




\section{Results and Discussion}

\subsection{Synthesis of o-Carboxamido Stilbene}

The synthesis of $o$-carboxamido stilbenes have been described in Scheme 2. Substituted benzaldehydes $\mathbf{2 a}-\mathbf{2 d}$ were reacted with methyltriphenylphosphoniumiodide in the presence of tert-BuOK in a Wittig reaction [16] to provide the styrene derivatives $\mathbf{3 f}-\mathbf{3 h}$ and $\mathbf{3 k}$; styrene $\mathbf{3 a}-\mathbf{3 e}, \mathbf{3 i}$ and 3j were purchased from Sigma-Aldrich (St. Louis, MO, USA) and were used without further purification. Iodo carboxamido was prepared in two ways (a) 2-iodoaniline was reacted with $\mathrm{NaH}$ and then acetic anhydride was added to give 2-iodoacetamide 5a; (b) A cooled solution $\left(0-5{ }^{\circ} \mathrm{C}\right)$ of 2-iodoaniline and triethylamine, was added with acyl chloride to give $\mathbf{5 b}-\mathbf{5 f}$ [18]. The iodo carboxamido $\mathbf{5 a}-\mathbf{5 f}$ were coupled with the styrenes $\mathbf{3 a}-\mathbf{3 k}$ using the Heck method by palladium (II) acetate catalyst to provide the $(E) o$-carboxamido stilbenes $\mathbf{6 a - 6 s}$ in good yield $[16,17]$.

Scheme 2. Synthesis of substituted styrenes by Wittig olefination, $o$-carboxamido stilbenes by Heck coupling reaction. Reagents and conditions. (i) $\mathrm{H}_{3} \mathrm{CP}\left(\mathrm{C}_{6} \mathrm{H}_{5}\right)_{3} \mathrm{Br}$, tert-BuOK, THF, $24 \mathrm{~h},-75^{\circ} \mathrm{C}$; (iia) $\mathrm{NaH}$, acetic anhydride, DMF or (iib) triethylamine $\left(\mathrm{Et}_{3} \mathrm{~N}\right)\left(0-5{ }^{\circ} \mathrm{C}\right)$, THF, acyl chloride; (iii) triethylamine $\left(\mathrm{Et}_{3} \mathrm{~N}\right), \mathrm{Pd}(\mathrm{II})$ acetate, $120^{\circ} \mathrm{C}$.<smiles>[R]c1cc(C=O)c([R])c([R])c1[R]</smiles>

Aldehyde (2)

2a: $\mathrm{R}_{1}=\mathrm{OCH}_{3}, \mathrm{R}_{2}=\mathrm{H}, \mathrm{R}_{3}=\mathrm{OCH}_{3}, \mathrm{R}_{4}=\mathrm{H}$

2b: $\mathrm{R}_{1}=\mathrm{H}, \mathrm{R}_{2}=\mathrm{H}, \mathrm{R}_{3}=\mathrm{H}, \mathrm{R}_{4}=\mathrm{OCH}_{3}$

2c: $\mathrm{R}_{1}=\mathrm{H}, \mathrm{R}_{2}=\mathrm{H}, \mathrm{R}_{3}=\mathrm{OCH}_{3}, \mathrm{R}_{4}=\mathrm{H}$ 2d: $R_{1}=H, R_{2}=P h, R_{3}=H, R_{4}=H$

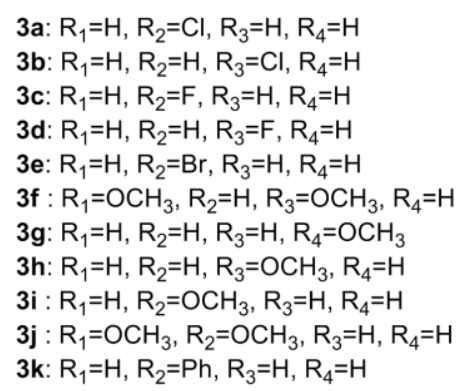

Styrene (3)
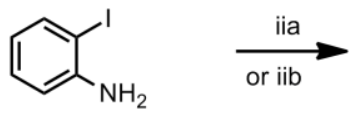<smiles>[R]C(=O)Nc1ccccc1I</smiles>
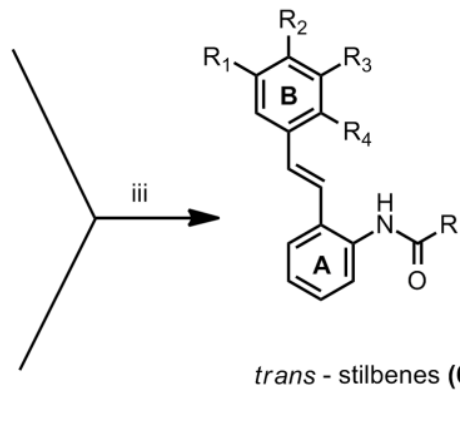

2-lodoaniline (4)
Protected amide (5)

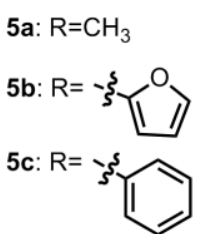

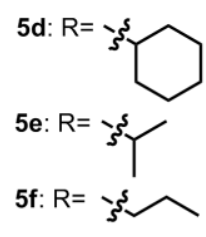

\subsection{Cytotoxic Evaluation of o-Carboxamido Stilbenes on Selected Human Cancer Cell Lines}

Resveratrol, a stilbene with antioxidant and antiproliferative properties, has been shown to inhibit a variety of primary tumors. However, the inhibitory effect is observed only at higher concentration $[19,20]$. In our effort to improve the cytotoxicity of resveratrol, a total of 19 resveratrol analogues bearing the $o$-carboxamido moiety were synthesized. These analogues together with 3 standards (cisplatin, resveratrol and vinblastine) were screened against 5 human cancer cell lines and 
one normal human cell line. Of the 19 analogues, 7 (6d, $6 \mathbf{e}, \mathbf{6 g}-\mathbf{6 i}, \mathbf{6 k}$ and $\mathbf{6 s})$ were found to be cytotoxic toward colon cancer cell lines (HT-29), 7 (6a, 6d, 6i, 61, 6n, 6p and 6s) toward estrogen-sensitive breast cancer (MCF-7), none towards estrogen-insensitive breast cancer (MDA-MB-231), 6 (6d, 6i-6l and 6p) toward prostate cancer (DU-145), 2 (6d and 6s) toward pancreatic cancer (BxPC-3) and none towards normal immortalized pancreatic cells (hTERT-HPNE). Analogue 6d showed cytotoxicity towards almost all cancer cell lines tested except for MDA-MB-231 (Table 1). Dose-response curves of the selected cytotoxic analogues toward HT-29, MCF-7, Bx-PC-3 and DU-145 are shown in Figure 1.

The resveratrol analogue $\mathbf{6 n}$, which has a bulky phenyl group attached to the amide and two methoxy group at ring $\mathrm{B}$, proved the most potent against estrogen-sensitive breast cancer cell line (MCF-7). The analogue has an $\mathrm{IC}_{50}$ of $21.24 \mu \mathrm{M}$ which is four times lower than that of resveratrol $\left(\mathrm{IC}_{50}=85.71 \mu \mathrm{M}\right)$ and comparable with that of vinblastine $\left(\mathrm{IC}_{50}=21.00 \mu \mathrm{M}\right)$. Interestingly, all the analogues that possess cytotoxic activity towards MCF-7 lost their inhibition when tested on estrogen-insensitive breast cancer (MDA-MB-231). The differences between these cancer cell lines are that MCF-7 possesses the estrogen receptor whereas MDA-MB-231 does not. This selective cytotoxic activity is also observed with resveratrol where its $\mathrm{IC}_{50}$ is $85.71 \mu \mathrm{M}$ in $\mathrm{MCF}-7$, and 143.57 $\mu \mathrm{M}$ in MDA-MB-231. This observation is due to the similar structure of resveratrol to the synthetic estrogen (diethylstilbestrol) and can act as a weak competitor in binding to the estrogen receptors [21]. The selective cytotoxicity towards estrogen-sensitive breast cancer cell line (MCF-7) lead us to hypothesize that the analogues $(\mathbf{6 a}, 6 \mathbf{d}, \mathbf{6 i}, \mathbf{6}, \mathbf{6 n}, \mathbf{6 p}$ and $\mathbf{6 s}$ ) may have similar estrogen receptor binding properties in MCF-7. Therefore, these analogues may be potential leads for the development of therapeutic agents for hormone-dependent tumors.

The structural activity relationship showed that analogues with a furan moiety at ring A and methoxy group at ring B have improved cytotoxicity toward the colon cancer cell line (HT-29) when compared with resveratrol. Almost all analogues with the furan moiety showed potent cytotoxicity, in particular analogue $6 \mathbf{i}\left(\mathrm{IC}_{50}=7.51 \mu \mathrm{M}\right)$ showed ten-fold improved cytotoxicity compared with resveratrol $\left(\mathrm{IC}_{50}=72.9 \mu \mathrm{M}\right)$ and four-fold to cisplatin $\left(\mathrm{IC}_{50}=30.61 \mu \mathrm{M}\right)$. Significant cytotoxicity is also observed in the prostate cancer cell line (DU-145) with analogue $\mathbf{6 d}$ having an $\mathrm{IC}_{50}$ value of $16.68 \mu \mathrm{M}$, which represents a six-fold increase in potency compared with resveratrol $\left(\mathrm{IC}_{50}=107.92 \mu \mathrm{M}\right)$. This improvement can be attributed to the acetyl group attached to the amide and fluorine, which is an electron withdrawing group at the meta position of the ring B in compound $\mathbf{6 d}$. Together with $\mathbf{6 d}$ $\left(\mathrm{IC}_{50}=129.78 \mu \mathrm{M}\right)$, compound $\mathbf{6 s}\left(\mathrm{IC}_{50}=66.30 \mu \mathrm{M}\right)$ having a propyl group attached to the amide, showed selective cytotoxic activity towards the pancreatic cancer cell line, BxPC-3, while sparing $\left(\mathrm{IC}_{50}>200 \mu \mathrm{M}\right)$ a normal pancreatic cell line (hTERT-HPNE). All the standards (cisplatin, vinblastine and resveratrol) showed no discrimination in their cytotoxicity between normal and cancer pancreatic cells. In chemotherapy, anticancer drugs that are selective towards cancer cells could reduce severe side-effects toward normal cells in the patient. Therefore, the analogues may offer an improved chemotherapy outcome for cancer patients compared to existing anticancer drugs. 


\section{Experimental Section}

\subsection{General}

All spectral data were obtained on the following instruments: Infrared spectra were recorded on a Perkin Elmer FTIR Spectrum RX-1 spectrometer at wavenumber from 4000-400 $\mathrm{cm}^{-1}$. Nuclear magnetic resonance (NMR) spectra were obtained on a JEOL JNM-LA 400 and JEOL ECA-400. Spectra are reported in units of ppm on the $\delta$ scale, relative to chloroform and the coupling constants are given in Hz. Ultra Violet (UV) spectra were recorded from wavelength 190-400 nm, in methanol, on a Shimadzu UV-Visible Spectrophotometer 1650. Mass spectra were measured using Agilent 6530 Accurate-Mass $Q$-TOF LC/MS system. Melting points were determined with Mel-Temp II melting point apparatus.

\subsection{Material}

Human cancer cell lines were obtained from American Type Culture Collection (ATCC) (Manassas, VA, USA). Dulbecco's modified Eagle's medium (DMEM), 100 mM non-essential amino acids, phosphate buffer solution ( $\mathrm{pH} 7.2$ ), $50 \mu \mathrm{g} / \mathrm{mL}$ gentamicin and $2.5 \mu \mathrm{g} / \mathrm{mL}$ amphotericin B were purchased from Invitrogen Corporation (Carlsbad, CA, USA). $200 \mathrm{mM}$ L-glutamine, foetal bovine serum, $0.25 \%$ trypsin-EDTA, dimethyl sulphoxide (DMSO), cisplatin, resveratrol and vinblastine sulphate were purchased from Sigma-Aldrich (St. Louis, MO, USA). MTS [3-(4,5-dimethylthiazol-2yl)-5-(3-carboxymethoxyphenyl)-2-(4-sulphophenyl)-2H-tetrazolium, inner salt] assay kit (CellTiter $96^{\circledR}$ $\mathrm{AQ}_{\text {ueous }}$ One Solution) was obtained from Promega (Madison, WI, USA).

Figure 1. Dose-response curves of selected $o$-carboxamido stilbenes on human cancer cell lines.
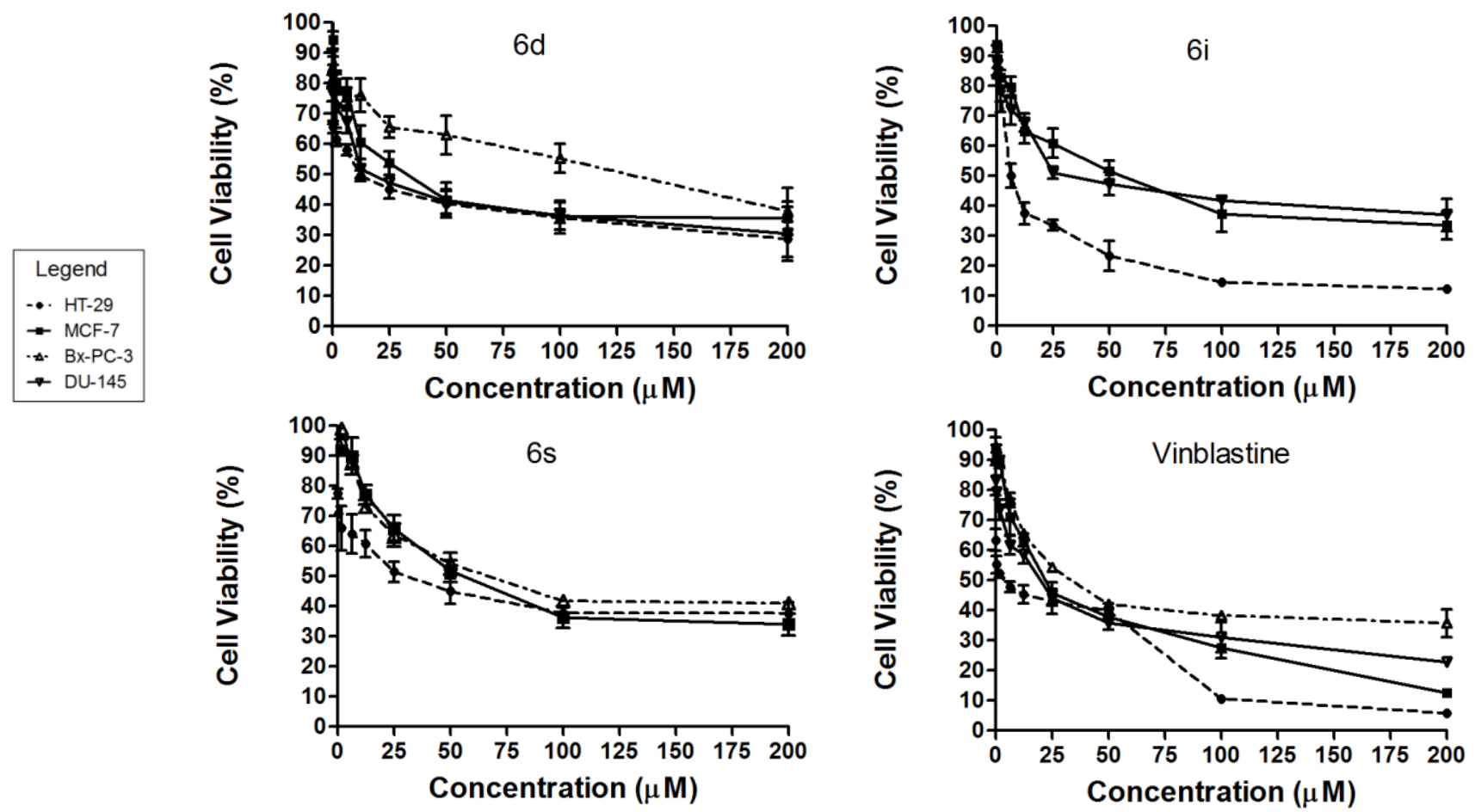
Figure 1. Cont.
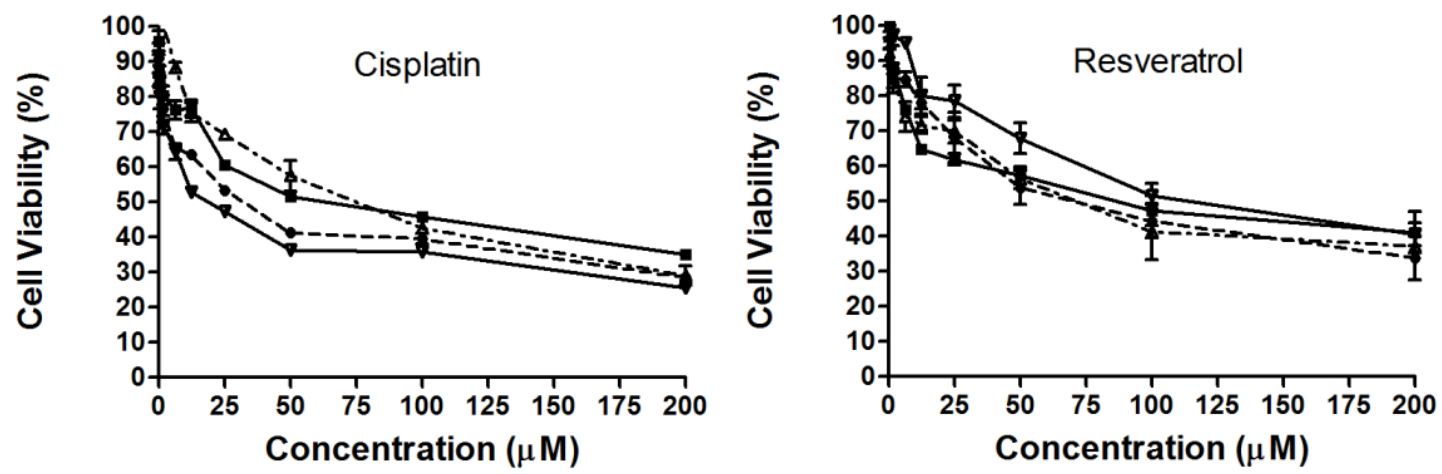

Table 1. Cytotoxic evaluation of $o$-carboxamido stilbenes on human cancer cell lines.

\begin{tabular}{ccccc}
\hline \multirow{2}{*}{ Entry } & \multicolumn{4}{c}{$\mathbf{I C}_{\mathbf{5 0}} / \boldsymbol{\mu M}(\boldsymbol{n}=\mathbf{3})$} \\
\cline { 2 - 5 } HT-29 & MCF-7 & Bx-PC-3 & DU-145 \\
\hline Vinblastin (Positive control) & $4.40 \pm 2.70$ & $21.00 \pm 2.33$ & $33.04 \pm 2.14$ & $20.31 \pm 7.76$ \\
Cisplatin (Positive control) & $30.61 \pm 2.34$ & $55.04 \pm 5.25$ & $71.54 \pm 5.36$ & $22.68 \pm 1.14$ \\
Resveratrol (Control) & $72.9 \pm 2.4$ & $85.71 \pm 1.70$ & $71.85 \pm 1.55$ & $107.92 \pm 1.57$ \\
$\mathbf{6 a}$ & $>200$ & $97.00 \pm 4.79$ & $>200$ & $>200$ \\
$\mathbf{6 b}$ & $>200$ & $>200$ & $>200$ & $>200$ \\
$\mathbf{6 c}$ & $>200$ & $>200$ & $>200$ & $>200$ \\
$\mathbf{6 d}$ & $11.40 \pm 7.35$ & $32.52 \pm 5.16$ & $129.78 \pm 4.36$ & $16.68 \pm 1.86$ \\
$\mathbf{6 e}$ & $15.92 \pm 3.85$ & $>200$ & $>200$ & $>200$ \\
$\mathbf{6 f}$ & $>200$ & $>200$ & $>200$ & $>200$ \\
$\mathbf{6 g}$ & $11.06 \pm 0.27$ & $>200$ & $>200$ & $>200$ \\
$\mathbf{6 h}$ & $18.62 \pm 0.56$ & $>200$ & $>200$ & $>200$ \\
$\mathbf{6 i}$ & $7.51 \pm 0.53$ & $53.32 \pm 5.63$ & $>200$ & $29.19 \pm 1.44$ \\
$\mathbf{6 j}$ & $>200$ & $>200$ & $>200$ & $42.25 \pm 2.02$ \\
$\mathbf{6 k}$ & $15.60 \pm 2.10$ & $>200$ & $>200$ & $56.83 \pm 2.37$ \\
$\mathbf{6}$ & $>200$ & $115.83 \pm 2.90$ & $>200$ & $92.79 \pm 4.85$ \\
$\mathbf{6 m}$ & $>200$ & $>200$ & $>200$ & $>200$ \\
$\mathbf{6 n}$ & $>200$ & $21.24 \pm 1.01$ & $>200$ & $>200$ \\
$\mathbf{6 0}$ & $>200$ & $>200$ & $>200$ & $>200$ \\
$\mathbf{6 p}$ & $>200$ & $128.16 \pm 7.58$ & $>200$ & $67.89 \pm 3.97$ \\
$\mathbf{6 q}$ & $>200$ & $>200$ & $>200$ & $>200$ \\
$\mathbf{6 r}$ & $>200$ & $>200$ & $>200$ & $>200$ \\
$\mathbf{6 s}$ & $29.11 \pm 2.73$ & $52.04 \pm 7.62$ & $66.30 \pm 1.14$ & $>200$ \\
\hline
\end{tabular}

\subsection{Chemical}

Unless otherwise noted, materials were purchased from commercial suppliers and used without purification. THF was freshly distilled over calcium hydride. DMF was dried over molecular sieves $4 \AA$ (Sigma-Aldrich, St. Louis, MO, USA) prior to use. Column chromatography was performed using Merck silica gel $(0.040-0.063 \mathrm{~mm})$. For thin layer chromatography, Merck TLC aluminum sheets (silica gel $60 F_{254}$ ) were used; centrifugal chromatography, Merck silica gel $60 P F_{254}$ containing gypsum were used. 


\subsection{Procedure for the Preparation of Compounds}

\subsubsection{General Procedure for Styrene}

To a suspension of methyltriphenylphosphonium iodide (1 equiv) in dry THF (25 mL), potassium tert-butoxide (1 equiv) was added in one portion. The mixture was stirred for $1 \mathrm{~h}$ at $-70{ }^{\circ} \mathrm{C}$ to $-80{ }^{\circ} \mathrm{C}$. The appropriate aldehyde ( 1 equiv) was added to the solution. The ice bath was removed and the mixture was allowed to warm to room temperature. After consumption of starting material to form the product, the reaction was quenched with saturated ammonium chloride solution. The mixture was extracted with ethyl acetate and washed with plenty of distilled water. The resulting organic fractions were combined and solvent was removed under reduced pressure to yield crude product. Purification by column chromatography afforded the desired product. The procedure for compounds $\mathbf{3 f}, \mathbf{3 g}, \mathbf{3 h}$ and 3k is attached in Appendix.

1,3-methoxy-5-vinylbenzene, 3f. ${ }^{1} \mathrm{H} \mathrm{NMR}\left(\mathrm{CDCl}_{3}, 400 \mathrm{MHz}\right) \delta: 6.66(\mathrm{dd}, J=17.5,10.7 \mathrm{~Hz}, 1 \mathrm{H})$, $6.59(\mathrm{~d}, J=2.2 \mathrm{~Hz}, 2 \mathrm{H}), 6.41(\mathrm{t}, J=2.2 \mathrm{~Hz}, 1 \mathrm{H}), 5.75(\mathrm{dd}, J=17.6,1.0 \mathrm{~Hz}, 1 \mathrm{H}), 5.26(\mathrm{dd}, J=10.9$, $1.0 \mathrm{~Hz}, 1 \mathrm{H}), 3.80\left(\mathrm{~s}, 6 \mathrm{H}, 2 \times \mathrm{OCH}_{3}\right) ;{ }^{13} \mathrm{C} \mathrm{NMR}\left(\mathrm{CDCl}_{3}, 100 \mathrm{MHz}\right): 160.8,139.5,136.8,114.2,104.2$, $99.9,55.1\left(2 \times \mathrm{OCH}_{3}\right)$.

1-methoxy-2-vinylbenzene, 3g. ${ }^{1} \mathrm{H} \mathrm{NMR}\left(\mathrm{CDCl}_{3}, 400 \mathrm{MHz}\right) \delta: 7.46(\mathrm{dd}, J=7.8,1.8 \mathrm{~Hz}, 1 \mathrm{H}), 7.23$ (t, $J=7.8 \mathrm{~Hz}, 1 \mathrm{H}), 7.04(\mathrm{dd}, J=17.8,11.4 \mathrm{~Hz}, 1 \mathrm{H}), 6.93(\mathrm{t}, J=7.3 \mathrm{~Hz}, 1 \mathrm{H}), 6.87(\mathrm{~d}, J=8.2 \mathrm{~Hz}, 1 \mathrm{H})$, $5.73(\mathrm{dd}, J=17.8,1.4 \mathrm{~Hz}, 1 \mathrm{H}), 5.25(\mathrm{dd}, J=9.1,1.4 \mathrm{~Hz}, 1 \mathrm{H}), 3.84\left(\mathrm{~s}, 3 \mathrm{H}, \mathrm{OCH}_{3}\right) ;{ }^{13} \mathrm{C} \mathrm{NMR}\left(\mathrm{CDCl}_{3}\right.$, $100 \mathrm{MHz}): 156.9,131.9,129.0,126.9,126.7,120.8,114.6,111.0,55.6$.

1-methoxy-3-vinylbenzene, 3h. ${ }^{1} \mathrm{H}$ NMR $\left(\mathrm{CDCl}_{3}, 400 \mathrm{MHz}\right) \delta: 7.26(\mathrm{t}, J=8.0 \mathrm{~Hz}, 1 \mathrm{H}), 7.03(\mathrm{t}$, $J=7.8 \mathrm{~Hz}, 1 \mathrm{H}), 6.98(\mathrm{~s}, 1 \mathrm{H}), 6.83(\mathrm{dd}, J=8.2 \mathrm{~Hz}, 2.8 \mathrm{~Hz}, 1 \mathrm{H}), 6.71(\mathrm{dd}, J=17.8 \mathrm{~Hz}, 11.0 \mathrm{~Hz}, 1 \mathrm{H})$, $5.77(\mathrm{~d}, J=17.8 \mathrm{~Hz}, 1 \mathrm{H}), 5.27(\mathrm{~d}, J=11.0 \mathrm{~Hz}, 1 \mathrm{H}), 3.83\left(\mathrm{~s}, \mathrm{OCH}_{3}, 3 \mathrm{H}\right) ;{ }^{13} \mathrm{C} \mathrm{NMR}\left(\mathrm{CDCl}_{3}\right.$, $100 \mathrm{MHz})$ : 159.9, 139.1, 136.9, 129.6, 119.1, 114.2, 113.5, 111.6, $55.3\left(\mathrm{OCH}_{3}\right)$.

4-vinyl-1,1'-biphenyl, 3k. ${ }^{1} \mathrm{H}$ NMR $\left(\mathrm{CDCl}_{3}, 400 \mathrm{MHz}\right) \delta: 7.60(\mathrm{~d}, J=6.8 \mathrm{~Hz}, 2 \mathrm{H}), 7.57(\mathrm{~d}, J=8.2 \mathrm{~Hz}$, 2H), $7.49(\mathrm{~d}, J=8.7 \mathrm{~Hz}, 2 \mathrm{H}), 7.44(\mathrm{t}, J=7.5 \mathrm{~Hz}, 2 \mathrm{H}), 7.34(\mathrm{t}, J=7.3 \mathrm{~Hz}, 1 \mathrm{H}), 6.76(\mathrm{dd}, J=17.8$, $11.0 \mathrm{~Hz}, 1 \mathrm{H}), 5.80(\mathrm{~d}, J=17.8 \mathrm{~Hz}, 1 \mathrm{H}), 5.28(\mathrm{~d}, J=11.0 \mathrm{~Hz}, 1 \mathrm{H}) ;{ }^{13} \mathrm{C} \mathrm{NMR}\left(\mathrm{CDCl}_{3}, 100 \mathrm{MHz}\right)$ : $140.9,140.7,136.7,136.5,128.9,127.5,127.4,127.1,126.8,114.0$.

\subsubsection{General Procedure for the Preparation of $N$-(2-iodophenyl)acylamide}

As described in [18] a solution of an appropriate acyl chloride (1 equiv) in $5 \mathrm{~mL}$ of dry THF was added dropwise to a stirred, cooled $\left(0-5{ }^{\circ} \mathrm{C}\right.$ ) solution of 2-iodoaniline ( 1 equiv) and $\mathrm{Et}_{3} \mathrm{~N}$ ( 1 equiv) in $20 \mathrm{~mL}$ of dry THF. The ice bath was then removed and the mixture stirred vigorously overnight at room temperature. Solid $\mathrm{Et}_{3} \mathrm{~N} \cdot \mathrm{HCl}$ was then filtered off and washed with $\mathrm{THF}(3 \times 5 \mathrm{~mL})$. The resulting organic fractions were combined and THF was removed under reduced pressure to yield crude amides. Recrystallization from hexanes/chloroform and drying in vacuum produced the desired product. The procedure for compounds $\mathbf{5 a}-\mathbf{5 f}$ is attached in Appendix.

$N$-(2-iodophenyl)acetamide, 5a. $M p 103-105{ }^{\circ} \mathrm{C} .{ }^{1} \mathrm{H}$ NMR $\left(\mathrm{CDCl}_{3}, 400 \mathrm{MHz}\right) \delta: 8.17(\mathrm{~d}, J=7.6 \mathrm{~Hz}$, $1 \mathrm{H}), 7.75$ (d, $J=7.8 \mathrm{~Hz}, 1 \mathrm{H}), 7.40$ (br s, 1H, NH), 7.32 (t, $J=7.3 \mathrm{~Hz}, 1 \mathrm{H}), 6.82$ (t, $J=7.4 \mathrm{~Hz}, 1 \mathrm{H}$ ), 
$2.22\left(\mathrm{~s}, 3 \mathrm{H}, \mathrm{CH}_{3}\right) ;{ }^{13} \mathrm{C} \mathrm{NMR}\left(\mathrm{CDCl}_{3}, 100 \mathrm{MHz}\right): 168.1,138.8,138.2,129.2,126.0,122.1,90.0$, $24.8\left(\mathrm{CH}_{3}\right)$.

$N$-(2-iodophenyl)furan-2-carboxamide, 5b. $M p$ 80-81 ${ }^{\circ} \mathrm{C}$; IR (NaCl): 3364, 1683, 1582, 1526, 1430, 1304, 1162, 1010, $750 \mathrm{~cm}^{-1}$; UV $(\mathrm{MeOH})_{\max } \mathrm{nm}: 257,231 ;{ }^{1} \mathrm{H} \mathrm{NMR}\left(\mathrm{CDCl}_{3}, 400 \mathrm{MHz}\right) \delta: 8.52$ (br s, $1 \mathrm{H}, \mathrm{NH},), 8.39$ (dd, $J=8.7,1.4 \mathrm{~Hz}, 1 \mathrm{H}), 7.80(\mathrm{dd}, J=7.8,1.4 \mathrm{~Hz}, 1 \mathrm{H}), 7.56(\mathrm{~d}, J=1.4 \mathrm{~Hz}, 1 \mathrm{H})$, $7.36(\mathrm{td}, J=8.7,1.4 \mathrm{~Hz}, 1 \mathrm{H}), 7.26(\mathrm{~d}, J=3.7 \mathrm{~Hz}, 1 \mathrm{H}), 6.85(\mathrm{td}, J=7.8,1.4 \mathrm{~Hz}, 1 \mathrm{H}), 6.57(\mathrm{dd}$, $J=3.6,1.8 \mathrm{~Hz}, 1 \mathrm{H}) ;{ }^{13} \mathrm{C} \mathrm{NMR}\left(\mathrm{CDCl}_{3}, 100 \mathrm{MHz}\right): 156.1,147.7,144.8,139.0,138.0,129.4,126.1$, 121.7, 115.8, 112.8, 89.9; HRMS (+ESI) $[\mathrm{M}+\mathrm{H}]^{+}: 313.9671, \mathrm{C}_{11} \mathrm{H}_{9} \mathrm{INO}_{2}$ requires 313.9672.

$N$-(2-iodophenyl)benzamide, 5c. $M p$ 135-137 ${ }^{\circ} \mathrm{C} ;{ }^{1} \mathrm{H}$ NMR $\left(\mathrm{CDCl}_{3}, 400 \mathrm{MHz}\right) \delta: 8.46(\mathrm{~d}, J=8.3 \mathrm{~Hz}$, $1 \mathrm{H}), 8.30$ (br s, 1H, NH), 7.96-7.98 (m, 2H), $7.82(\mathrm{dd}, J=7.9,1.5 \mathrm{~Hz}, 1 \mathrm{H}), 7.51-7.61(\mathrm{~m}, 3 \mathrm{H})$, $7.41(\mathrm{td}, J=7.8,1.5 \mathrm{~Hz}, 1 \mathrm{H}), 6.89(\mathrm{td}, J=7.7,1.5 \mathrm{~Hz}, 1 \mathrm{H}) ;{ }^{13} \mathrm{C} \mathrm{NMR}\left(\mathrm{CDCl}_{3}, 100 \mathrm{MHz}\right)$ : $165.4,138.9,138.4,134.6,132.3,129.5,129.0,127.3,126.2,121.9,90.3$.

$N$-(2-iodophenyl)cyclohexanecarboxamide, 5d. $M p$ 134-146 ${ }^{\circ} \mathrm{C} ;{ }^{1} \mathrm{H}$ NMR $\left(\mathrm{CDCl}_{3}, 400 \mathrm{MHz}\right) \delta$ : $8.24(\mathrm{~d}, J=8.2 \mathrm{~Hz}, 1 \mathrm{H}), 7.75(\mathrm{dd}, J=8.2,1.4 \mathrm{~Hz}, 1 \mathrm{H}), 7.51(\mathrm{br} \mathrm{s}, 1 \mathrm{H}, \mathrm{NH}), 7.32$ (td, $J=7.4,1.4 \mathrm{~Hz}$, $1 \mathrm{H}), 6.82(\mathrm{td}, J=7.8,1.8 \mathrm{~Hz}, 1 \mathrm{H}), 2.30(\mathrm{tt}, J=11.7,3.4 \mathrm{~Hz}, 1 \mathrm{H}), 1.23-2.06(\mathrm{~m}, 10 \mathrm{H}) ;{ }^{13} \mathrm{C} \mathrm{NMR}$ $\left(\mathrm{CDCl}_{3}, 100 \mathrm{MHz}\right)$ : 174.4, 138.8, 138.3, 129.3, 125.9, 122.1, 90.2, 46.7, $29.8\left(\mathrm{CH}_{2}\right), 25.8\left(\mathrm{CH}_{2}\right)$.

$N$-(2-iodophenyl)isobutyramide, 5e. $M p$ 110-111 ${ }^{\circ} \mathrm{C} ;{ }^{1} \mathrm{H}$ NMR $\left(\mathrm{CDCl}_{3}, 400 \mathrm{MHz}\right) \delta: 8.23$ (d, $J=8.0 \mathrm{~Hz}, 1 \mathrm{H},), 7.75(\mathrm{~d}, J=8.1 \mathrm{~Hz}, 1 \mathrm{H}), 7.51(\mathrm{br} \mathrm{s}, 1 \mathrm{H}, \mathrm{NH}), 7.32(\mathrm{t}, J=7.6 \mathrm{~Hz}, 1 \mathrm{H}), 6.82(\mathrm{t}, J=7.3 \mathrm{~Hz}$, $1 \mathrm{H}), 2.59$ (septet, $J=7.0 \mathrm{~Hz}, 1 \mathrm{H}), 1.30\left(\mathrm{~d}, J=6.8 \mathrm{~Hz}, 6 \mathrm{H}, 2 \times \mathrm{CH}_{3}\right) ;{ }^{13} \mathrm{C} \mathrm{NMR}\left(\mathrm{CDCl}_{3}, 100 \mathrm{MHz}\right)$ : $175.3,138.8,138.2,129.4,125.9,122.0,90.2,37.1,19.7\left(\mathrm{CH}_{3}\right)$.

$N$-(2-iodophenyl)butyramide, 5f. $M p 81-83{ }^{\circ} \mathrm{C} ;{ }^{1} \mathrm{H}$ NMR $\left(\mathrm{CDCl}_{3}, 400 \mathrm{MHz}\right) \delta: 8.22(\mathrm{~d}, J=7.8 \mathrm{~Hz}$, $1 \mathrm{H}), 7.76$ (dd, $J=8.0,1.4 \mathrm{~Hz}, 1 \mathrm{H}), 7.43$ (br s, $1 \mathrm{H}, \mathrm{NH}$ ), 7.33 (td, $J=8.0,1.4 \mathrm{~Hz}, 1 \mathrm{H}), 6.82$ (t, $J=7.8 \mathrm{~Hz}$, $1 \mathrm{H}), 2.40(\mathrm{~d}, J=7.6 \mathrm{~Hz}, 2 \mathrm{H}), 1.79$ (sextet, $J=7.8 \mathrm{~Hz}, 2 \mathrm{H}), 1.03\left(\mathrm{t}, J=7.3 \mathrm{~Hz}, 3 \mathrm{H}, \mathrm{CH}_{3}\right) ;{ }^{13} \mathrm{C} \mathrm{NMR}$ $\left(\mathrm{CDCl}_{3}, 100 \mathrm{MHz}\right): 171.3,138.8,138.3,129.4,126.0,122.1,90.0,40.0,19.2,13.7\left(\mathrm{CH}_{3}\right)$.

\subsubsection{General Procedure for Stilbene}

In a dry two neck flask, the appropriate $N$-(2-iodophenyl)acylamide ( 1 equiv) was dissolved in dry DMF and stirred under nitrogen. The solution was heated up to $120^{\circ} \mathrm{C}$ and refluxed for a few minutes. Palladium (II) acetate ( 0.01 equiv) was added, followed by triethylamine (3.5 equiv) into the mixture. Lastly, the appropriate styrene (1.2 equiv) was added into the reaction flask. The mixture was heated at $120{ }^{\circ} \mathrm{C}$ under nitrogen until consumption of $N$-(2-iodophenyl)acylamide (check via TLC). The reaction mixture was quenched with saturated ammonium chloride aqueous solution. It was then extracted with ethyl acetate and washed with plenty of distilled water. The resulting organic fractions were combined, dried over anhydrous sodium sulphate and solvent was removed under reduced pressure to yield crude product. Purification by column chromatography afforded the desired products. The procedure for compounds 6a-6s is attached in Appendix.

(E)- $N$-(2-(4-chlorostyryl)phenyl)acetamide, 6a [22]. $M p$ 201-202 ${ }^{\circ} \mathrm{C}$; IR (neat): 3281, 1642, 1531, 1299, 951, 803, $748 \mathrm{~cm}^{-1} ;{ }^{1} \mathrm{H} \mathrm{NMR}\left(\mathrm{CDCl}_{3}, 400 \mathrm{MHz}\right) \delta: 7.42(\mathrm{~d}, J=8.3 \mathrm{~Hz}, 2 \mathrm{H}), 7.33(\mathrm{~d}$, $J=8.5 \mathrm{~Hz}, 2 \mathrm{H}), 6.95(\mathrm{~d}, J=16.0 \mathrm{~Hz}, 1 \mathrm{H}), 7.11(\mathrm{~d}, J=16.0 \mathrm{~Hz}, 1 \mathrm{H}), 7.75(\mathrm{~d}, J=8.2 \mathrm{~Hz}, 1 \mathrm{H}), 7.18(\mathrm{t}$, 
$J=7.3 \mathrm{~Hz}, 1 \mathrm{H}), 7.52(\mathrm{~d}, J=7.3 \mathrm{~Hz}, 1 \mathrm{H}), 2.21\left(\mathrm{~s}, 3 \mathrm{H}, \mathrm{CH}_{3}\right) ;{ }^{13} \mathrm{C} \mathrm{NMR}\left(\mathrm{CDCl}_{3}, 100 \mathrm{MHz}\right) 135.5$, $127.8,128.9,133.7,128.9,127.8,130.9,124.1,130.4,134.6,124.7,128.5,125.8,126.7,24.2,168.6$ $(\mathrm{C}=\mathrm{O})$; HRMS (+ESI) $[\mathrm{M}+\mathrm{H}]^{+}:$272.0873, $\mathrm{C}_{16} \mathrm{H}_{15} \mathrm{CINO}$ requires 272.0842 .

(E)-N-(2-(3-chlorostyryl)phenyl)acetamide, 6b. IR (neat): 3281, 1655, 1530, 1298, 951, 773, $749 \mathrm{~cm}^{-1} ;{ }^{1} \mathrm{H} \mathrm{NMR}\left(\mathrm{CDCl}_{3}, 400 \mathrm{MHz}\right) \delta: 7.47$ (br s, 1H), 7.35-7.24 (m, 4H), 6.92 (d, $J=16.0 \mathrm{~Hz}$, $1 \mathrm{H}), 7.10(\mathrm{~d}, J=16.0 \mathrm{~Hz}, 1 \mathrm{H}), 7.73(\mathrm{~d}, J=8.2 \mathrm{~Hz}, 1 \mathrm{H}), 7.18(\mathrm{~d}, J=7.8 \mathrm{~Hz}, 1 \mathrm{H}), 7.52(\mathrm{~d}, J=7.8 \mathrm{~Hz}$, 1H), $2.21\left(\mathrm{~s}, 3 \mathrm{H}, \mathrm{CH}_{3}\right) ;{ }^{13} \mathrm{C} \mathrm{NMR}\left(\mathrm{CDCl}_{3}, 100 \mathrm{MHz}\right)$ 139.0, 126.9, 134.8, 125.0, 128.8, 130.1, 130.8, 125.1, 130.3, 134.8, 124.8, 128.1, 125.9, 126.5, $24.4\left(\mathrm{CH}_{3}\right), 168.8(\mathrm{C}=\mathrm{O})$; HRMS (+ESI) $[\mathrm{M}+\mathrm{H}]^{+}$: 272.0800, $\mathrm{C}_{16} \mathrm{H}_{15} \mathrm{ClNO}$ requires 272.0842 .

(E)-N-(2-(4-fluorostyryl)phenyl)acetamide, 6c. IR (neat): 3259, 1659, 1527, 1297, 963, $818 \mathrm{~cm}^{-1}$; ${ }^{1} \mathrm{H} \mathrm{NMR}\left(\mathrm{CDCl}_{3}, 400 \mathrm{MHz}\right) \delta: 7.46(\mathrm{~d}, J=6.0 \mathrm{~Hz}, 2 \mathrm{H}), 7.01(\mathrm{~d}, J=8.2 \mathrm{~Hz}, 2 \mathrm{H}), 6.95(\mathrm{~d}, J=16.5 \mathrm{~Hz}$, $1 \mathrm{H}), 7.01-7.05(\mathrm{~m}, 1 \mathrm{H}), 7.73(\mathrm{~d}, J=8.2 \mathrm{~Hz}, 1 \mathrm{H}), 7.26(\mathrm{t}, J=6.8 \mathrm{~Hz}, 1 \mathrm{H}), 7.19$ (t, $J=7.8 \mathrm{~Hz}, 1 \mathrm{H})$, $7.51(\mathrm{~d}, J=7.8 \mathrm{~Hz}, 1 \mathrm{H}), 2.21\left(\mathrm{~s}, 3 \mathrm{H}, \mathrm{CH}_{3}\right) ;{ }^{13} \mathrm{C} \mathrm{NMR}\left(\mathrm{CDCl}_{3}, 100 \mathrm{MHz}\right) 163.7,128.1,115.7,161.2$, 115.5, 128.1, 131.0, 123.2, 130.4, 134.4, 124.5, 128.2, 125.6, 126.6, $24.1\left(\mathrm{CH}_{3}\right), 168.6(\mathrm{C}=\mathrm{O})$; HRMS (+ESI) $[\mathrm{M}+\mathrm{H}]^{+}: 256.1139, \mathrm{C}_{16} \mathrm{H}_{15} \mathrm{FNO}$ requires 256.1138 .

(E)-N-(2-(3-fluorostyryl)phenyl)acetamide, 6d. IR (neat): 3281, 1642, 1531, 1299, 951, 803, $748 \mathrm{~cm}^{-1} ;{ }^{1} \mathrm{H} \mathrm{NMR}\left(\mathrm{CDCl}_{3}, 400 \mathrm{MHz}\right) \delta: 7.14$ (br s, $\left.1 \mathrm{H}\right), 6.94(\mathrm{td}, J=1.4,8.2 \mathrm{~Hz}, 1 \mathrm{H}), 7.29(\mathrm{t}$, $J=7.4 \mathrm{~Hz}, 1 \mathrm{H}), 7.16-7.05(\mathrm{~m}, 3 \mathrm{H}), 6.81(\mathrm{~d}, J=16.5 \mathrm{~Hz}, 1 \mathrm{H}), 7.04-7.10(\mathrm{~m}, 1 \mathrm{H}), 7.48(\mathrm{~d}, J=7.8 \mathrm{~Hz}$, $1 \mathrm{H}), 7.43(\mathrm{~d}, J=7.8 \mathrm{~Hz}, 1 \mathrm{H}), 2.10\left(\mathrm{~s}, 3 \mathrm{H}, \mathrm{CH}_{3}\right) ;{ }^{13} \mathrm{C} \mathrm{NMR}\left(\mathrm{CDCl}_{3}, 100 \mathrm{MHz}\right) 139.6,112.9,162.0$, 113.1, 130.2, 122.8, 130.3, 125.3, 130.4, 134.6, 124.7, 128.5, 125.8, 126.7, $24.2\left(\mathrm{CH}_{3}\right), 168.6$; HRMS $(+\mathrm{ESI})[\mathrm{M}+\mathrm{H}]^{+}: 256.1810, \mathrm{C}_{16} \mathrm{H}_{15} \mathrm{FNO}$ requires 256.1138 .

(E)-N-(2-(4-bromostyryl)phenyl)acetamide, 6e. IR (neat): 3315, 1664, 1557, 1259, 1029, 798, $772 \mathrm{~cm}^{-1}$; ${ }^{1} \mathrm{H}$ NMR $\left(\mathrm{CDCl}_{3}, 400 \mathrm{MHz}\right) \delta: 7.48(\mathrm{~d}, J=8.2 \mathrm{~Hz}, 2 \mathrm{H}), 7.34(\mathrm{~d}, J=8.2 \mathrm{~Hz}, 2 \mathrm{H}), 6.91(\mathrm{~d}$, $J=16.5 \mathrm{~Hz}, 1 \mathrm{H}), 7.12(\mathrm{~d}, J=16.5 \mathrm{~Hz}, 1 \mathrm{H}), 7.70(\mathrm{~d}, J=7.8 \mathrm{~Hz}, 1 \mathrm{H}), 7.27(\mathrm{~d}, J=7.8 \mathrm{~Hz}, 1 \mathrm{H}), 7.17$ (t, $J=7.8 \mathrm{~Hz}, 1 \mathrm{H}), 7.52(\mathrm{~d}, J=7.8 \mathrm{~Hz}, 1 \mathrm{H}), 2.19\left(\mathrm{~s}, 3 \mathrm{H}, \mathrm{CH}_{3}\right) ;{ }^{13} \mathrm{C} \mathrm{NMR}\left(\mathrm{CDCl}_{3}, 100 \mathrm{MHz}\right) 136.1$, 132.0, 128.2, 121.9, 128.2, 132.0, 130.9, 124.3, 130.5, 134.7, 124.9, 128.6, 126.0, 126.8, $24.3\left(\mathrm{CH}_{3}\right)$, 168.9; HRMS (+ESI) $[\mathrm{M}+\mathrm{H}]^{+}: 316.0334, \mathrm{C}_{16} \mathrm{H}_{15} \mathrm{BrNO}$ requires 316.0377.

(E)-N-(2-(3,5-dimethoxystyryl)phenyl)acetamide, 6f. IR (NaCl): 3262, 1654, 1153, $773 \mathrm{~cm}^{-1}$. UV $(\mathrm{MeOH})_{\max } \mathrm{nm}: 305,215 ;{ }^{1} \mathrm{H} \mathrm{NMR}\left(\mathrm{CDCl}_{3}, 400 \mathrm{MHz}\right) \delta: 7.77(\mathrm{~d}, J=8.0 \mathrm{~Hz}, 1 \mathrm{H}), 7.49(\mathrm{~d} J=8.0 \mathrm{~Hz}$, $1 \mathrm{H}), 7.27(\mathrm{t}, J=8.0 \mathrm{~Hz}, 1 \mathrm{H}), 7.20(\mathrm{br} \mathrm{s}, 1 \mathrm{H}, \mathrm{NH}), 7.15(\mathrm{t}, J=8.0 \mathrm{~Hz}, 1 \mathrm{H}), 7.08(\mathrm{~d}, J=16.1 \mathrm{~Hz}, 1 \mathrm{H})$, $6.88(\mathrm{~d}, J=16.1 \mathrm{~Hz}, 1 \mathrm{H}), 6.63(\mathrm{~d}, J=2.2 \mathrm{~Hz}, 2 \mathrm{H}), 6.41(\mathrm{t}, J=2.2 \mathrm{~Hz}, 1 \mathrm{H}), 3.82\left(\mathrm{~s}, 6 \mathrm{H}, \mathrm{OCH}_{3}\right), 2.19$ $\left(\mathrm{s}, 3 \mathrm{H}, \mathrm{CH}_{3}\right) .{ }^{13} \mathrm{C} \mathrm{NMR}\left(\mathrm{CDCl}_{3}, 100 \mathrm{MHz}\right): 168.8,161.1,139.1,134.7,132.4,130.3,128.4,126.9$, 125.7, 124.4, 124.2, 105.0, 100.1, 55.4, 24.3; HRMS (+ESI) $[\mathrm{M}+\mathrm{H}]^{+}: 298.1430, \mathrm{C}_{18} \mathrm{H}_{20} \mathrm{NO}_{3}$ requires 298.1443 .

(E)-N-(2-(2-methoxystyryl)phenyl)furan-2-carboxamide, 6g [15]. Mp 128-129 ${ }^{\circ} \mathrm{C}$; IR (NaCl): $3285,1671,1585,1304,1247,751 \mathrm{~cm}^{-1}$; UV (MeOH) $\max$ nm: 262, 321; ${ }^{1} \mathrm{H} \mathrm{NMR}\left(\mathrm{CDCl}_{3}, 400 \mathrm{MHz}\right)$ $\delta: 8.25$ (br s, 1H, NH), 8.04 (d, $J=8.2 \mathrm{~Hz}, 1 \mathrm{H}), 7.60$ (dd, $J=7.8,1.0 \mathrm{~Hz}, 1 \mathrm{H}), 7.56$ (dd, $J=7.6$, $1.4 \mathrm{~Hz}, 1 \mathrm{H}), 7.49(\mathrm{~d}, J=1.0 \mathrm{~Hz}, 1 \mathrm{H}), 7.40(\mathrm{~d}, J=16.5 \mathrm{~Hz}, 1 \mathrm{H}), 7.29$ (d, $J=16.8 \mathrm{~Hz}, 1 \mathrm{H}), 7.28-7.33$ $(\mathrm{m}, 3 \mathrm{H}), 7.20(\mathrm{t}, J=7.1 \mathrm{~Hz}, 1 \mathrm{H}), 6.98(\mathrm{t}, J=7.6 \mathrm{~Hz}, 1 \mathrm{H}), 6.91(\mathrm{~d}, J=8.2 \mathrm{~Hz}, 1 \mathrm{H}), 6.55(\mathrm{dd}$, 
$J=3.7,1.8 \mathrm{~Hz}, 1 \mathrm{H}), 3.85\left(\mathrm{~s}, 3 \mathrm{H} \mathrm{OCH}_{3}\right) ;{ }^{13} \mathrm{C} \mathrm{NMR}\left(\mathrm{CDCl}_{3}, 100 \mathrm{MHz}\right): 157.3,156.4,148.0,144.5$, 134.1, 130.7, 129.3, 128.3, 128.2, 127.3, 127.2, 126.2, 125.6, 123.7, 123.5, 120.9, 115.4, 112.7 , 111.1, $55.5\left(\mathrm{OCH}_{3}\right)$; HRMS (+ESI) $[\mathrm{M}+\mathrm{H}]^{+}: 320.1285, \mathrm{C}_{20} \mathrm{H}_{18} \mathrm{NO}_{3}$ requires 320.1287.

(E)- $N$-(2-(3-methoxystyryl)phenyl)furan-2-carboxamide, 6h [15]. $M p$ 96-97 ${ }^{\circ} \mathrm{C} ; \mathrm{IR}(\mathrm{NaCl}): 3285$, 1669, 1585, 1521, 1304, 1163, $755 \mathrm{~cm}^{-1}$; UV $(\mathrm{MeOH})_{\max } \mathrm{nm}: 210,264,300 ;{ }^{1} \mathrm{H} \mathrm{NMR}\left(\mathrm{CDCl}_{3}\right.$, $400 \mathrm{MHz}) \delta: 8.17($ br s, $1 \mathrm{H}, \mathrm{NH}), 8.02(\mathrm{~d}, J=8.2 \mathrm{~Hz}, 1 \mathrm{H}), 7.55(\mathrm{~d}, J=7.8 \mathrm{~Hz}, 1 \mathrm{H}), 7.50(\mathrm{~d}$, $J=1.0 \mathrm{~Hz}, 1 \mathrm{H}), 7.33(\mathrm{t}, J=7.2 \mathrm{~Hz}, 1 \mathrm{H}), 7.29(\mathrm{t}, J=8.0 \mathrm{~Hz}, 1 \mathrm{H}), 7.26(\mathrm{~d}, J=3.2 \mathrm{~Hz}, 1 \mathrm{H}), 7.22(\mathrm{~d}$, $J=16.0 \mathrm{~Hz}, 1 \mathrm{H}), 7.21(\mathrm{t}, J=7.6 \mathrm{~Hz}, 1 \mathrm{H}), 7.12(\mathrm{~d}, J=7.8 \mathrm{~Hz}, 1 \mathrm{H}), 7.04(\mathrm{~s}, 1 \mathrm{H}), 7.02(\mathrm{~d}, J=16.5 \mathrm{~Hz}$, $1 \mathrm{H}), 6.85(\mathrm{dd}, J=8.5,2.3 \mathrm{~Hz}, 1 \mathrm{H}), 6.56(\mathrm{dd}, J=3.7,1.8 \mathrm{~Hz}, 1 \mathrm{H}), 3.83\left(\mathrm{~s}, 3 \mathrm{H}, \mathrm{OCH}_{3}\right) ;{ }^{13} \mathrm{C} \mathrm{NMR}$ $\left(\mathrm{CDCl}_{3}, 100 \mathrm{MHz}\right): 160.0,156.4,147.9,144.5,138.5,134.2,132.9,130.1,129.9,128.6,127.3,125.6$, 123.6, 119.4, 115.6, 113.7, 112.7, 112.3, $55.4\left(\mathrm{OCH}_{3}\right)$; HRMS (+ESI) $[\mathrm{M}+\mathrm{H}]^{+}: 320.1282, \mathrm{C}_{20} \mathrm{H}_{18} \mathrm{NO}_{3}$ requires 320.1287 .

(E)- $N$-(2-(4-methoxystyryl)phenyl)furan-2-carboxamide, 6i [15]. $M p$ 120-121 ${ }^{\circ} \mathrm{C}$; IR (NaCl): 3276 ,

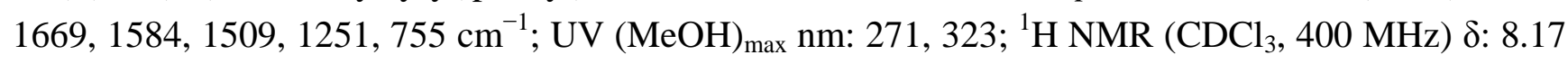
(br s, 1H, NH), $8.04(\mathrm{~d}, J=8.2 \mathrm{~Hz}, 1 \mathrm{H}), 7.54(\mathrm{~d}, J=7.8 \mathrm{~Hz}, 1 \mathrm{H}), 7.50(\mathrm{~d}, J=1.0 \mathrm{~Hz}, 1 \mathrm{H}), 7.47$ (t, $J=7.6 \mathrm{~Hz}, 2 \mathrm{H}), 7.31(\mathrm{td}, J=7.3,1.3 \mathrm{~Hz}, 1 \mathrm{H}), 7.26(\mathrm{~d}, J=3.7 \mathrm{~Hz}, 1 \mathrm{H}), 7.19(\mathrm{t}, J=7.6 \mathrm{~Hz}, 1 \mathrm{H}), 7.09$ $(\mathrm{d}, J=16.5 \mathrm{~Hz}, 1 \mathrm{H}), 7.00(\mathrm{~d}, J=16.5 \mathrm{~Hz}, 1 \mathrm{H}), 6.92(\mathrm{t}, J=7.6 \mathrm{~Hz}, 2 \mathrm{H}), 6.56(\mathrm{dd}, J=3.2,1.8 \mathrm{~Hz}, 1 \mathrm{H})$, $3.83\left(\mathrm{~s}, 3 \mathrm{H}, \mathrm{OCH}_{3}\right) ;{ }^{13} \mathrm{C} \mathrm{NMR}\left(\mathrm{CDCl}_{3}, 100 \mathrm{MHz}\right): 159.8,156.3,148.0,144.5,134.0,132.7,130.4$, 129.9, 128.2, 128.1, 127.1, 125.6, 123.5, 121.0, 115.5, 114.3, 112.7, $55.5\left(\mathrm{OCH}_{3}\right) ; \mathrm{HRMS}(+\mathrm{ESI})[\mathrm{M}+\mathrm{H}]^{+}$: $320.1302, \mathrm{C}_{20} \mathrm{H}_{18} \mathrm{NO}_{3}$ requires 320.1287 .

(E)- $N$-(2-(3,4-dimethoxystyryl)phenyl)furan-2-carboxamide, $\mathbf{6 j}$ [15]. $M p$ 142-144 ${ }^{\circ} \mathrm{C}$; IR (NaCl): 3239, 1651, 1575, 1514, 1456, 1265, 1157, 1137, 1027, $751 \mathrm{~cm}^{-1}$; UV (MeOH) $\max$ nm: 210, 252, 326; ${ }^{1} \mathrm{H} \mathrm{NMR}\left(\mathrm{CDCl}_{3}, 400 \mathrm{MHz}\right) \delta: 8.19$ (br s, $\left.1 \mathrm{H}, \mathrm{NH}\right), 8.00(\mathrm{~d}, J=8.2 \mathrm{~Hz}, 1 \mathrm{H}), 7.52(\mathrm{~d}, J=7.8 \mathrm{~Hz}, 1 \mathrm{H})$, $7.47(\mathrm{dd}, J=1.8,1.0 \mathrm{~Hz}, 1 \mathrm{H}), 7.29(\mathrm{t}, J=7.8 \mathrm{~Hz}, 1 \mathrm{H}), 7.23(\mathrm{~d}, J=2.8 \mathrm{~Hz}, 1 \mathrm{H}), 7.18(\mathrm{t}, J=7.8 \mathrm{~Hz}$, 1H), $7.07(\mathrm{~d}, J=16.5 \mathrm{~Hz}, 1 \mathrm{H}), 7.05(\mathrm{~d}, J=8.9 \mathrm{~Hz}, 1 \mathrm{H}), 7.03(\mathrm{~s}, 1 \mathrm{H}), 6.96(\mathrm{~d}, J=16.5 \mathrm{~Hz}, 1 \mathrm{H}), 6.85$ $(\mathrm{d}, J=8.2,2.3 \mathrm{~Hz}, 1 \mathrm{H}), 6.54(\mathrm{dd}, J=3.4,1.8 \mathrm{~Hz}, 1 \mathrm{H}), 3.89\left(\mathrm{~s}, 3 \mathrm{H}, \mathrm{OCH}_{3}\right), 3.88\left(\mathrm{~s}, 3 \mathrm{H}, \mathrm{OCH}_{3}\right) ;{ }^{13} \mathrm{C}$ NMR $\left(\mathrm{CDCl}_{3}, 100 \mathrm{MHz}\right): 156.4$, 149.4, 149.2, 148.0, 144.5, 134.0, 132.7, 130.4, 130.2, 128.2, 127.1, 125.6, 123.7, 121.4, 120.1, 115.4, 112.7, 111.4, 109.3, $56.1\left(\mathrm{OCH}_{3}\right), 56.0\left(\mathrm{OCH}_{3}\right)$; HRMS (+ESI) $[\mathrm{M}+\mathrm{H}]^{+}: 320.1411, \mathrm{C}_{21} \mathrm{H}_{20} \mathrm{NO}_{4}$ requires 320.1392 .

(E)- $N$-(2-(3,5-dimethoxystyryl)phenyl)furan-2-carboxamide, 6k [15]. $M p$ 109-110 ${ }^{\circ} \mathrm{C}$; IR (NaCl): 3282, 1670, 1590, 1520, 1455, 1303, 1204, 1152, 1065, $755 \mathrm{~cm}^{-1}$; UV (MeOH) $\max$ nm: 239, 269, 308; ${ }^{1} \mathrm{H}$ NMR $\left(\mathrm{CDCl}_{3}, 400 \mathrm{MHz}\right) \delta: 8.16(\mathrm{br} s, 1 \mathrm{H}, \mathrm{NH}), 8.04(\mathrm{~d}, J=7.8 \mathrm{~Hz}, 1 \mathrm{H}), 7.54(\mathrm{dd}$, $J=7.8,1.4 \mathrm{~Hz}, 1 \mathrm{H}), 7.50(\mathrm{~d}, J=1.0 \mathrm{~Hz}, 1 \mathrm{H}), 7.33(\mathrm{td}, J=7.8,1.4 \mathrm{~Hz}, 1 \mathrm{H}), 7.26(\mathrm{~d}, J=3.2 \mathrm{~Hz}, 1 \mathrm{H})$, $7.21(\mathrm{~d}, J=16.0 \mathrm{~Hz}, 1 \mathrm{H}), 7.20(\mathrm{t}, J=7.5 \mathrm{~Hz}, 1 \mathrm{H}), 6.99(\mathrm{~d}, J=16.0 \mathrm{~Hz}, 1 \mathrm{H}), 6.66(\mathrm{~s}, 2 \mathrm{H}, \mathrm{H}-2)$, $6.56(\mathrm{dd}, J=3.6,1.8 \mathrm{~Hz}, 1 \mathrm{H}), 6.43(\mathrm{t}, J=1.8 \mathrm{~Hz}, 1 \mathrm{H}), 3.81\left(\mathrm{~s}, 6 \mathrm{H}, 2 \mathrm{xOCH}_{3}\right) ;{ }^{13} \mathrm{C} \mathrm{NMR}\left(\mathrm{CDCl}_{3}\right.$, $100 \mathrm{MHz})$ : 161.1, 156.3, 147.9, 144.5, 139.1, 134.2, 133.0, 129.9, 128.6, 127.3, 125.6, 123.9, 123.6, 115.6, 112.7, 105.0, 100.3, $55.9\left(2 \times \mathrm{OCH}_{3}\right)$; HRMS (+ESI) $[\mathrm{M}+\mathrm{H}]^{+}: 350.1412, \mathrm{C}_{21} \mathrm{H}_{20} \mathrm{NO}_{4}$ requires 350.1392 .

(E)-N-(2-(2-(biphenyl-4-yl)vinyl)phenyl)furan-2-carboxamide, $6 \mathbf{l}$ [15]. $M p$ 142-143 ${ }^{\circ} \mathrm{C}$; IR (NaCl): 3283, 1671, 1585, 1521, 1487, 1452, 1304, $762 \mathrm{~cm}^{-1}$; UV $(\mathrm{MeOH})_{\max } \mathrm{nm}:$ 204, 267, 323; 
${ }^{1} \mathrm{H}$ NMR $\left(\mathrm{CDCl}_{3}, 400 \mathrm{MHz}\right) \delta: 8.19$ (br s, 1H, NH), $8.04(\mathrm{~d}, J=7.8 \mathrm{~Hz}, 1 \mathrm{H}), 7.58-7.64(\mathrm{~m}, 7 \mathrm{H}), 7.52$ $(\mathrm{t}, J=1.0 \mathrm{~Hz}, 1 \mathrm{H}), 7.44-7.48(\mathrm{~m}, 2 \mathrm{H}), 7.32-7.38(\mathrm{~m}, 2 \mathrm{H}), 7.21-7.30(\mathrm{~m}, 3 \mathrm{H}), 7.10(\mathrm{~d}, J=16.5 \mathrm{~Hz}$, $1 \mathrm{H}) ;{ }^{13} \mathrm{C} \mathrm{NMR}\left(\mathrm{CDCl}_{3}, 100 \mathrm{MHz}\right): 156.4,148.0,144.5,141.0,140.6,136.1,134.2,132.5,130.2$, 129.0, 128.6, 127.6, 127.5, 127.3, 127.0, 125.7, 123.7, 123.3, 115.6, 112.7; HRMS (+ESI) [M + Na $]^{+}$: $388.1324, \mathrm{C}_{27} \mathrm{H}_{22} \mathrm{NO}$ requires 388.1308. An X-ray of this compound was published in 2008 [23].

(E)-N-(2-(2-([1,1'-biphenyl]-4-yl)vinyl)phenyl)benzamide, 6m [15]. Mp 167-169 ${ }^{\circ} \mathrm{C}$; IR (NaCl): $3271,1648,1517,1487,1302,764 \mathrm{~cm}^{-1}$; UV $(\mathrm{MeOH})_{\max } \mathrm{nm}: 319 ;{ }^{1} \mathrm{H} \mathrm{NMR}\left(\mathrm{CDCl}_{3}, 400 \mathrm{MHz}\right) \delta$ : 8.05 (br s, 1H, NH), 7.91 (d, $J=7.3 \mathrm{~Hz}, 3 \mathrm{H}), 7.43-7.62(\mathrm{~m}, 12 \mathrm{H}), 7.31-7.36(\mathrm{~m}, 2 \mathrm{H}), 7.22-7.26(\mathrm{~m}$, 2H), $7.06(\mathrm{~d}, J=16.5 \mathrm{~Hz}, 1 \mathrm{H}) ;{ }^{13} \mathrm{C} \mathrm{NMR}\left(\mathrm{CDCl}_{3}, 100 \mathrm{MHz}\right): 166.0,140.9,140.6,136.1,134.8,134.7$, $132.2,132.1,131.0,129.0,128.5,127.5,127.3,127.2,127.1,127.0,126.0,124.7,123.5$; HRMS (+ESI) $[\mathrm{M}+\mathrm{H}]^{+}: 376.1691, \mathrm{C}_{27} \mathrm{H}_{22} \mathrm{NO}$ requires 376.1701 .

(E)-N-(2-(3,4-dimethoxystyryl)phenyl)benzamide, 6n [15]. Mp 169-171 ${ }^{\circ} \mathrm{C} ; \mathrm{IR}(\mathrm{NaCl}): 3273$, $3012,1646,1572,1509,1265,749 \mathrm{~cm}^{-1}$; UV (MeOH) $\max$ nm: 231, 324; ${ }^{1} \mathrm{H} \mathrm{NMR}\left(\mathrm{CDCl}_{3}, 400 \mathrm{MHz}\right)$ $\delta: 8.03$ (br s, 1H, NH), $7.87(\mathrm{~d}, J=7.8 \mathrm{~Hz}, 3 \mathrm{H}), 7.51-7.55(\mathrm{~m}, 2 \mathrm{H}), 7.44(\mathrm{t}, J=7.3 \mathrm{~Hz}, 2 \mathrm{H}), 7.28$ (t, $J=7.8 \mathrm{~Hz}, 2 \mathrm{H}), 7.20(\mathrm{t}, J=7.5 \mathrm{~Hz}, 1 \mathrm{H}), 7.04(\mathrm{~d}, J=16.0 \mathrm{~Hz}, 1 \mathrm{H}), 6.98(\mathrm{~d}, J=9.2 \mathrm{~Hz}, 1 \mathrm{H}), 6.97$ (s, $1 \mathrm{H}), 6.93(\mathrm{~d}, J=16.0 \mathrm{~Hz}, 1 \mathrm{H}), 6.82(\mathrm{~d}, J=8.2 \mathrm{~Hz}, 1 \mathrm{H}), 3.86\left(\mathrm{~s}, 3 \mathrm{H}, \mathrm{OCH}_{3}\right), 3.83\left(\mathrm{~s}, 3 \mathrm{H}, \mathrm{OCH}_{3}\right)$; ${ }^{13} \mathrm{C} \mathrm{NMR}\left(\mathrm{CDCl}_{3}, 100 \mathrm{MHz}\right): 166.0,149.4,149.2,134.8,134.7,132.5,132.0,131.1,130.2,128.9$, 128.2, 127.3, 127.0, 125.9, 124.5, 121.7, 120.1, 111.3, 109.1, $56.0\left(\mathrm{OCH}_{3}\right), 55.9\left(\mathrm{OCH}_{3}\right)$; HRMS (+ESI) $[\mathrm{M}+\mathrm{H}]^{+}: 360.1594, \mathrm{C}_{23} \mathrm{H}_{22} \mathrm{NO}_{3}$ requires 360.1600 .

(E)-N-(2-(4-methoxystyryl)phenyl)benzamide, 6o. IR (neat): 3283, 1644, 1512, 1482, 1248, 1178, 1027, $749 \mathrm{~cm}^{-1}$; ${ }^{1} \mathrm{H}$ NMR (400MHz, $\left.\mathrm{CDCl}_{3}\right) \delta: 3.82\left(\mathrm{~s}, 3 \mathrm{H} . \mathrm{OCH}_{3}\right), 6.87(\mathrm{dt}, J=3.2,8.7 \mathrm{~Hz}, 2 \mathrm{H}), 6.98$ $(\mathrm{d}, J=16.0 \mathrm{~Hz}, 1 \mathrm{H}), 7.06(\mathrm{~d}, J=16.5 \mathrm{~Hz}, 1 \mathrm{H}), 7.21(\mathrm{t}, J=7.6 \mathrm{~Hz}, 1 \mathrm{H}), 7.32(\mathrm{t}, J=7.8 \mathrm{~Hz}, 1 \mathrm{H}), 7.41$ $(\mathrm{t}, J=4.3 \mathrm{~Hz}, 2 \mathrm{H}), 7.48(\mathrm{t}, J=7.6 \mathrm{~Hz}, 2 \mathrm{H}), 7.54(\mathrm{t},, J=7.3 \mathrm{~Hz} 2 \mathrm{H}), 7.89(\mathrm{~d}, J=7.3 \mathrm{~Hz}, 2 \mathrm{H}), 7.97$ (d, $J=7.8 \mathrm{~Hz}, 1 \mathrm{H}) ;{ }^{13} \mathrm{C} \mathrm{NMR}\left(\mathrm{CDCl}_{3}, 100 \mathrm{MHz}\right): 132.0,129.0,127.2,134.8,134.6,124.1,128.2,125.8$, 127.1, 130.9, 121.1, 132.9, 129.8, 128.1, 114.3, 159.8, 165.5; HRMS (+ESI) $[\mathrm{M}+\mathrm{H}]^{+}: 330.1493$, $\mathrm{C}_{22} \mathrm{H}_{20} \mathrm{NO}_{2}$ requires 330.1494 .

(E)-N-(2-(3,4-dimethoxystyryl)phenyl)cyclohexanecarboxamide, 6p [15]. Mp 204-206 ${ }^{\circ} \mathrm{C}$; IR (NaCl): 2930, 2853, 1682, 1515, 1449, 1269, 1137, 1026, $757 \mathrm{~cm}^{-1}$; UV (MeOH) $\max$ nm: 217, 300; ${ }^{1} \mathrm{H} \mathrm{NMR}\left(\mathrm{CDCl}_{3}, 400 \mathrm{MHz}\right) \delta: 7.77(\mathrm{~d}, J=8.2 \mathrm{~Hz}, 1 \mathrm{H}), 7.50(\mathrm{~d}, J=7.3 \mathrm{~Hz}, 1 \mathrm{H}), 7.25(\mathrm{td}, J=8.0,1.4 \mathrm{~Hz}$, 1H), 7.21 (br s, 1H, NH), 7.17 (d, $J=7.8 \mathrm{~Hz}, 1 \mathrm{H}), 7.16(\mathrm{~d}, J=7.6 \mathrm{~Hz}, 1 \mathrm{H}), 7.03$ (d, $J=7.3 \mathrm{~Hz}, 1 \mathrm{H})$, $7.02(\mathrm{~s}, 1 \mathrm{H}), 6.97(\mathrm{~d}, J=16.5 \mathrm{~Hz}, 1 \mathrm{H}), 6.91(\mathrm{~d}, J=16.5 \mathrm{~Hz}, 1 \mathrm{H}), 3.91\left(\mathrm{~s}, 3 \mathrm{H}, \mathrm{OCH}_{3}\right), 3.90(\mathrm{~s}, 3 \mathrm{H}$,

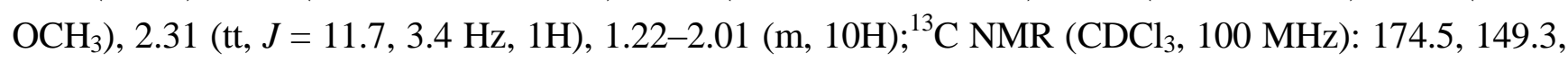
149.2, 134.6, 132.2, 130.8, 130.2, 128.1, 126.8, 125.6, 124.4, 121.7, 120.1, 111.3, 108.9, 56.1 $\left(\mathrm{OCH}_{3}\right)$, $55.9\left(\mathrm{OCH}_{3}\right), 46.3,29.9,25.8$; HRMS (+ESI) $[\mathrm{M}+\mathrm{H}]^{+}: 366.2069, \mathrm{C}_{23} \mathrm{H}_{28} \mathrm{NO}_{3}$ requires 366.2069.

(E)- $N$-(2-(3,4-dimethoxystyryl)phenyl)isobutyramide, 6q [15]. $M p$ 166-168 ${ }^{\circ} \mathrm{C}$; IR (NaCl): 3274 , 1652, 1516, 1269, 1141, 1025, 961, 801, $752 \mathrm{~cm}^{-1}$; UV $(\mathrm{MeOH})_{\max } \mathrm{nm}: 210,236,325 ;{ }^{1} \mathrm{H}$ NMR $\left(\mathrm{CDCl}_{3}, 400 \mathrm{MHz}\right) \delta: 7.74(\mathrm{~d}, J=7.8 \mathrm{~Hz}, 1 \mathrm{H}), 7.49(\mathrm{~d}, J=7.3 \mathrm{~Hz}, 1 \mathrm{H}), 7.31$ (br s, 1H, NH), 7.24 (t, $J=7.8 \mathrm{~Hz}, 1 \mathrm{H}), 7.15(\mathrm{t}, J=7.6 \mathrm{~Hz}, 1 \mathrm{H}), 7.01(\mathrm{~d}, J=7.8 \mathrm{~Hz}, 1 \mathrm{H}), 7.00(\mathrm{~s}, 1 \mathrm{H}), 6.97(\mathrm{~d}, J=16.4 \mathrm{~Hz}$, $1 \mathrm{H}), 6.90(\mathrm{~d}, J=16.5 \mathrm{~Hz}, 1 \mathrm{H}), 6.85(\mathrm{~d}, J=8.7 \mathrm{~Hz}, 1 \mathrm{H}), 3.89\left(\mathrm{~s}, 6 \mathrm{H}, 2 \mathrm{xOCH}_{3}\right), 2.54-2.61(\mathrm{~m}, 1 \mathrm{H})$, $1.27(\mathrm{~d}, J=6.9 \mathrm{~Hz}, 6 \mathrm{H}) ;{ }^{13} \mathrm{C} \mathrm{NMR}\left(\mathrm{CDCl}_{3}, 100 \mathrm{MHz}\right)$ : 175.6, 149.3, 149.2, 134.6, 132.1, 130.9, 
$130.2,128.1,126.8,125.7,124.5,121.7,120.1,111.3,108.9,56.1\left(\mathrm{OCH}_{3}\right), 55.9\left(\mathrm{OCH}_{3}\right), 36.5$, $19.9\left(2 \times \mathrm{CH}_{3}\right) ; \mathrm{HRMS}(+\mathrm{ESI})[\mathrm{M}+\mathrm{H}]^{+}: 326.1759, \mathrm{C}_{20} \mathrm{H}_{24} \mathrm{NO}_{3}$ requires 326.1756.

(E)-N-(2-(4-methoxystyryl)phenyl)isobutyramide, 6r. IR (NaCl): 3267, 2966, 1510, 1267, 1033, $750 \mathrm{~cm}^{-1} ;{ }^{1} \mathrm{H} \mathrm{NMR}\left(400 \mathrm{MHz}, \mathrm{CDCl}_{3}\right) \delta: 1.27(\mathrm{~d}, J=6.9 \mathrm{~Hz}, 6 \mathrm{H}), 2.53-2.59(\mathrm{~m}, 1 \mathrm{H}), 3.82(\mathrm{~s}, 3 \mathrm{H}$, $\left.\mathrm{OCH}_{3}\right), 7.79(\mathrm{~d}, J=7.8 \mathrm{~Hz}, 1 \mathrm{H}), 7.23(\mathrm{td}, J=1.0,8.0 \mathrm{~Hz}, 1 \mathrm{H}), 7.14(\mathrm{~d}, J=7.5 \mathrm{~Hz}, 1 \mathrm{H}), 7.48(\mathrm{~d}$, $J=7.8 \mathrm{~Hz}, 1 \mathrm{H}), 6.97(\mathrm{~d}, J=16.5 \mathrm{~Hz}, 1 \mathrm{H}), 6.92(\mathrm{~m}, 1 \mathrm{H}), 7.41(\mathrm{~d}, J=9.2 \mathrm{~Hz}, 2 \mathrm{H}), 6.89(\mathrm{~m}, 2 \mathrm{H})$, 7.33 (br s, $1 \mathrm{H}, \mathrm{NH}) ;{ }^{13} \mathrm{C} \mathrm{NMR}\left(\mathrm{CDCl}_{3}, 100 \mathrm{MHz}\right): 19.8\left(\mathrm{CH}_{3}\right), 36.5,55.4\left(\mathrm{OCH}_{3}\right), 134.6,124.2$, $128.0,125.5,126.9,130.7,121.3,132.0,129.9,128.0,114.3,175.5 ;$ HRMS (+ESI) $[\mathrm{M}+\mathrm{H}]^{+}$: 296.1649, $\mathrm{C}_{19} \mathrm{H}_{22} \mathrm{NO}_{2}$ requires 296.1651.

(E)-N-(2-(3,4-dimethoxystyryl)phenyl)butyramide, 6s [15]. $M p$ 139-140 ${ }^{\circ} \mathrm{C}$; IR (NaCl): 3280, 2963, 1510, 1267, 1025, $759 \mathrm{~cm}^{-1}$; UV $(\mathrm{MeOH})_{\max } \mathrm{nm}: 206,323 ;{ }^{1} \mathrm{H} \mathrm{NMR}\left(\mathrm{CDCl}_{3}, 400 \mathrm{MHz}\right) \delta$ : $7.63(\mathrm{~d}, J=7.8 \mathrm{~Hz}, 1 \mathrm{H}), 7.56(\mathrm{br} \mathrm{s}, 1 \mathrm{H}, \mathrm{NH}), 7.46(\mathrm{~d}, J=7.8 \mathrm{~Hz}, 1 \mathrm{H}), 7.18(\mathrm{t}, J=7.0 \mathrm{~Hz}, 1 \mathrm{H}), 7.11(\mathrm{t}$, $J=7.3 \mathrm{~Hz}, 1 \mathrm{H}), 6.98(\mathrm{~d}, J=7.8 \mathrm{~Hz}, 1 \mathrm{H}), 6.97(\mathrm{~s}, 1 \mathrm{H}), 6.95(\mathrm{~d}, J=15.6 \mathrm{~Hz}, 1 \mathrm{H}), 6.85(\mathrm{~d}$, $J=16.2 \mathrm{~Hz}, 1 \mathrm{H}), 6.81(\mathrm{~d}, J=8.2 \mathrm{~Hz}, 1 \mathrm{H}), 3.86\left(\mathrm{~s}, 3 \mathrm{H}, \mathrm{OCH}_{3}\right), 3.85\left(\mathrm{~s}, 3 \mathrm{H}, \mathrm{OCH}_{3}\right), 2.31(\mathrm{t}, J=7.3 \mathrm{~Hz}$, 2H), 1.69-1.75 (m, 2H, CH$), 0.97(\mathrm{t}, J=7.3 \mathrm{~Hz}, 3 \mathrm{H}) ;{ }^{13} \mathrm{C} \mathrm{NMR}\left(\mathrm{CDCl}_{3}, 100 \mathrm{MHz}\right): 172.0,149.2$, 149.1, 134.6, 131.6, 131.1, 130.3, 127.9, 126.5, 125.7, 124.9, 121.8, 120.1, 111.3, 109.1, $56.0\left(\mathrm{OCH}_{3}\right)$, $55.9\left(\mathrm{OCH}_{3}\right), 39.3,19.4,13.9\left(\mathrm{CH}_{3}\right)$; HRMS (+ESI) $[\mathrm{M}+\mathrm{H}]^{+}: 326.1755, \mathrm{C}_{20} \mathrm{H}_{24} \mathrm{NO}_{3}$ requires 326.1756.

\subsection{Cytotoxic Assays}

Cytotoxicity of the compounds were evaluated against a panel of 5 cancer cell lines; prostate (DU-145), pancreatic (BxPC-3), colon (HT-29), breast (MCF-7) and (MDA-MB-231); and one normal cell line, pancreatic (hTERT-HPNE). The cancer cell lines were chosen from the National Cancer Institute (NCI) list of 60 cancer cell lines for drug screening and drug treatment conditions adhered to NCI recommendations [24].

Cell lines were cultured in DMEM media supplemented with $2 \mathrm{mM}$ L-glutamine, $10 \%$ foetal bovine serum, $50 \mu \mathrm{g} / \mathrm{mL}$ gentamicin and $2.5 \mu \mathrm{g} / \mathrm{mL}$ amphotericin $\mathrm{B}$, maintained in a $37^{\circ} \mathrm{C}$ humid atmosphere of $5 \% \mathrm{CO}_{2}$ cell incubator. hTERT-HPNE cell line was cultured in the same DMEM with $10 \mathrm{ng} / \mathrm{mL}$ human recombinant epithelial growth factor as recommended by ATCC. Samples and drug standards (cisplatin, resveratrol and vinblastine) were dissolved in DMSO and immediately diluted with DMEM media to yield a final DMSO concentration of less than $0.5 \% \mathrm{v} / \mathrm{v}$.

Cells were plated into 96-well microplates at 5000-10,000 cells per well and maintained in the cell incubator for $24 \mathrm{~h}$. Then, $100 \mu \mathrm{L}$ of samples were introduced in triplicates to a final concentration of 0.1-200 $\mu \mathrm{M}$. Drug standards were also introduced to a final concentration of 0.03-2000 $\mu \mathrm{M}$ (cisplatin) $0.78-400 \mu \mathrm{M}$ (resveratrol) and 0.002-200 $\mu \mathrm{M}$ (vinblastine). Cells were further incubated for $48 \mathrm{~h}$ and then, cell viability was determined according to the manufacturer protocol of a commercial MTS assay kit (CellTiter $96^{\circledR}$ AQueous One Solution, Promega). Culture media were carefully refreshed with $100 \mu \mathrm{L}$ of DMEM media, followed by $20 \mu \mathrm{L}$ per well of MTS reagent. Microplates were returned to the incubator for 1-2 $\mathrm{h}$ and absorbance of the formazan product was read on a microplate reader at $490 \mathrm{~nm}$ with $690 \mathrm{~nm}$ as the background wavelength (Infinite 200, Tecan, Mannedorf, Swizerland). $\mathrm{IC}_{50}$ of samples and drug standards were determined using dose-response curves, and statistical 
analysis using student's $T$-test $(p<0.05)$ was performed in Prism 5.02 software (GraphPad Software Inc., La Jolla, CA, USA).

\section{Conclusions}

A total of 19 analogues of $o$-carboxamido stilbenes were synthesized using the Heck method. These analogues possessing the amide moiety with different substituent groups displayed varying cytotoxic activity toward various human cancer cell lines with the most potent compounds; compound $6 \mathbf{d}$ $\left(\mathrm{IC}_{50}=16.68 \mu \mathrm{M}\right.$, prostate cancer DU-145), compound $\mathbf{6 i}\left(\mathrm{IC}_{50}=7.51 \mu \mathrm{M}\right.$, colon cancer HT-29), compound 6n $\left(\mathrm{IC}_{50}=21.24 \mu \mathrm{M}\right.$, estrogen-sensitive breast cancer MCF-7) and compound 6s $\left(\mathrm{IC}_{50}=66.30 \mu \mathrm{M}\right.$, pancreatic cancer BxPC-3). Interestingly, all these potent compounds did not show any cytotoxicity toward the normal pancreatic cell line (hTERT-HPNE) compared to vinblastine, cisplastin and resveratrol which exhibited cytotoxicity toward the normal pancreatic cell line (hTERT-HPNE). These results provide progress in our knowledge to support future designs of stilbene-based anticancer drugs.

\section{Acknowledgments}

We are grateful to the University of Malaya Postgraduate Research Grant (PPP) (PV090/2011A) and (PV050/2012A), the Ministry of Higher Education (MOHE) Fundamental Research Grant Scheme (2010-0063-101-02), University of Malaya Research Grant (UMRG) (RP001/2012B) and ScienceFund (SF018-2013) for the financial supports.

\section{Conflicts of Interest}

The authors declare no conflict of interest.

\section{Appendix}

\section{Experimental Data}

1,3-methoxy-5-vinylbenzene, 3f. 3,5-methoxybenzaldehyde 2a (5.00 g, $30.09 \mathrm{mmol})$ was treated with methyltriphenylphosphonium iodide $(12.37 \mathrm{~g}, 30.61 \mathrm{mmol})$ and potassium tert-butoxide $(3.41 \mathrm{~g}$, $30.35 \mathrm{mmol}$ ) according to the general procedure. Purification by column chromatography (hexane/ethyl acetate, 98:2) afforded the product as colourless oil. Yield: $2.68 \mathrm{~g}$ (54\%).

1-methoxy-2-vinylbenzene, 3g. 2-methoxybenzaldehyde $2 \mathbf{b}$ (5.04 g, $37.00 \mathrm{mmol})$ was treated with methyltriphenylphosphonium iodide $(14.84 \mathrm{~g}, 36.72 \mathrm{mmol})$ and potassium tert-butoxide (4.13 g, $36.82 \mathrm{mmol}$ ) according to the general procedure. Purification by column chromatography (hexane/ethyl acetate, 98:2) afforded the product as colourless oil. Yield: $2.82 \mathrm{~g}$ (57\%).

1-methoxy-3-vinylbenzene, 3h. 3-methoxybenzaldehyde 2c (5.04 g, $36.76 \mathrm{mmol})$ was treated with methyltriphenylphosphonium iodide $(14.92 \mathrm{~g}, 36.91 \mathrm{mmol})$ and potassium tert-butoxide (4.24 $\mathrm{g}$, $37.79 \mathrm{mmol}$ ) according to the general procedure. Purification by column chromatography (hexane/ethyl acetate, 98:2) afforded the product as colourless oil. Yield: $2.95 \mathrm{~g} \mathrm{(60} \mathrm{( \% ).}$ 
4-vinyl-1,1'-biphenyl, 3k. Biphenyl-4-carbaldehyde 2d (0.99 g, $5.44 \mathrm{mmol})$ was treated with methyltriphenylphosphonium iodide $(2.25 \mathrm{~g}, 5.56 \mathrm{mmol})$ and potassium tert-butoxide $(0.62 \mathrm{~g}$, $5.50 \mathrm{mmol}$ ) according to the general procedure. Purification by column chromatography (hexane/ethyl acetate, 98:2) afforded the product as white solid. Yield: $0.54 \mathrm{~g}$ (55\%).

$N$-(2-iodophenyl)acetamide, 5a. To a stirred, cooled $\left(0-5{ }^{\circ} \mathrm{C}\right)$ solution of 2-iodoaniline $(2.53 \mathrm{~g}$, $11.57 \mathrm{mmol})$ in $20 \mathrm{~mL}$ of dry DMF, sodium hydride $(0.92 \mathrm{~g}, 23.14 \mathrm{mmol})$ and acetic anhydride $(5.40 \mathrm{~mL}, 61.75 \mathrm{mmol})$ was added into the reaction flask. Then ice bath was removed and the mixture was allowed to stir overnight at room temperature. Saturated ammonium chloride was added to the reaction mixture followed by extraction with ethyl acetate. The combined ethyl acetate extracts were then washed with distilled water to remove DMF. The solution was then filtered and dried over anhydrous sodium sulphate. The crude product, obtained after evaporation under reduced pressure was purified by column chromatography to give the purified product as yellowish solid. Yield: $1.82 \mathrm{~g} \mathrm{(60 \% ).}$

$N$-(2-iodophenyl)furan-2-carboxamide, 5b. 2-iodoaniline $(5.48 \mathrm{~g}, 25.03 \mathrm{mmol})$ was treated with furan-2-carbonyl chloride $(2.5 \mathrm{~mL}, 25.40 \mathrm{mmol})$ according to the general procedure. The crude product was purified by column chromatography (hexane/ethyl acetate, 90:10) to give a yellowish solid. Yield: $5.49 \mathrm{~g}(69 \%)$.

$N$-(2-iodophenyl)benzamide, 5c [18]. 2-iodoaniline (5.49 g, $25.05 \mathrm{mmol}$ ) was treated with benzoyl chloride $(2.9 \mathrm{~mL}, 24.98 \mathrm{mmol})$ according to the general procedure. Recrystalization of the crude product from hexanes/ $\mathrm{CHCl}_{3}$ afforded a yellowish solid. Yield: $6.55 \mathrm{~g}(81 \%)$.

$N$-(2-iodophenyl)cyclohexanecarboxamide, 5d [18]. 2-iodoaniline (5.50 g, $25.11 \mathrm{mmol})$ was treated with cyclohexanecarbonyl chloride $(3.4 \mathrm{~mL}, 25.04 \mathrm{mmol})$ according to the general procedure. Recrystalization of the crude product from hexanes/ $\mathrm{CHCl}_{3}$ afforded an off-white solid. Yield: $6.13 \mathrm{~g}(74 \%)$.

$N$-(2-iodophenyl)isobutyramide, 5e [18]. 2-iodoaniline $(5.49 \mathrm{~g}, 25.06 \mathrm{mmol})$ was treated with isobutyryl chloride $(2.70 \mathrm{~mL}, 25.59 \mathrm{mmol})$ according to the general procedure. Recrystalization of the crude product from hexanes/ $\mathrm{CHCl}_{3}$ afforded an off-white solid. Yield: $5.46 \mathrm{~g} \mathrm{(75 \% ).}$

$N$-(2-iodophenyl)butyramide, 5f [18]. 2-iodoaniline (2.19 g, $10.01 \mathrm{mmol})$ was treated with butyryl chloride $(1.0 \mathrm{~mL}, 10.26 \mathrm{mmol})$ according to the general procedure. Recrystalization of the crude product from hexanes/ $\mathrm{CHCl}_{3}$ afforded an off-white solid. Yield: $2.00 \mathrm{~g}(69 \%)$.

(E)- $N$-(2-(4-chlorostyryl)phenyl)acetamide, 6a [22]. Compound 5a (0.30 g, $1.15 \mathrm{mmol})$ was dissolved in $50 \mathrm{~mL}$ dry DMF. The solution was heated up to $120{ }^{\circ} \mathrm{C}$ and refluxed under nitrogen for a few minutes. Palladium (II) acetate $(2.6 \mathrm{mg}, 0.0115 \mathrm{mmol})$ was added, followed by triethylamine $(0.48 \mathrm{~mL}, 3.45 \mathrm{mmol})$ into the mixture. Compound $\mathbf{3 a}(0.20 \mathrm{~g}, 1.37 \mathrm{mmol})$ was added into the reaction flask. The mixture was reflux under nitrogen until consumption of compound 5a (check via TLC). The reaction mixture was treated according to the general procedure. Purification of the crude product by column chromatography (dichloromethane/ethyl acetate, 97:3) afforded an off-white solid. Yield: $0.11 \mathrm{~g}(35 \%)$.

(E)- $N$-(2-(3-chlorostyryl)phenyl)acetamide, 6b. Compound 5a $(0.30 \mathrm{~g}, 1.15 \mathrm{mmol})$ was dissolved in $50 \mathrm{~mL}$ dry DMF. The solution was heated up to $120^{\circ} \mathrm{C}$ and refluxed under nitrogen for a few minutes. 
Palladium (II) acetate $(2.6 \mathrm{mg}, 0.0115 \mathrm{mmol})$ was added, followed by triethylamine $(0.48 \mathrm{~mL}, 3.45 \mathrm{mmol})$ into the mixture. Compound $\mathbf{3 b}(0.17 \mathrm{~g}, 1.20 \mathrm{mmol})$ was added into the reaction flask. The mixture was reflux under nitrogen until consumption of compound 5a (check via TLC). The reaction mixture was treated according to the general procedure. Purification of the crude product by column chromatography (dichloromethane/ethyl acetate, 97:3) afforded an off-white solid. Yield: $0.09 \mathrm{~g}(27 \%)$.

(E)-N-(2-(4-fluorostyryl)phenyl)acetamide, 6c. Compound 5a $(0.30 \mathrm{~g}, 1.15 \mathrm{mmol})$ was dissolved in $50 \mathrm{~mL}$ dry DMF. The solution was heated up to $120{ }^{\circ} \mathrm{C}$ and refluxed under nitrogen for a few minutes. Palladium (II) acetate (2.6 $\mathrm{mg}, 0.0115 \mathrm{mmol})$ was added, followed by triethylamine $(0.48 \mathrm{~mL}, 3.45 \mathrm{mmol})$ into the mixture. Compound $3 \mathrm{c}(0.15 \mathrm{~g}, 1.20 \mathrm{mmol})$ was added into the reaction flask. The mixture was reflux under nitrogen until consumption of compound 5a (check via TLC). The reaction mixture was treated according to the general procedure. Purification of the crude product by column chromatography (dichloromethane/ethyl acetate, 97:3) afforded an off-white solid. Yield: $0.13 \mathrm{~g}(42 \%)$.

(E)- $N$-(2-(3-fluorostyryl)phenyl)acetamide, 6d. Compound 5a (1.0 g, $3.83 \mathrm{mmol})$ was dissolved in $20 \mathrm{~mL}$ dry DMF. The solution was heated up to $120^{\circ} \mathrm{C}$ and refluxed under nitrogen for a few minutes. Palladium (II) acetate $(17.2 \mathrm{mg}, \quad 0.0767 \mathrm{mmol})$ was added, followed by triethylamine $(1.9 \mathrm{~mL}, 13.41 \mathrm{mmol})$ into the mixture. Compound $\mathbf{3 d}(0.49 \mathrm{~g}, 4.00 \mathrm{mmol})$ was added into the reaction flask. The mixture was reflux under nitrogen until consumption of compound 5a (check via TLC). The reaction mixture was treated according to the general procedure. Purification of the crude product by column chromatography (dichloromethane/ethyl acetate, 97:3) afforded an off-white solid. Yield: $0.20 \mathrm{~g}(20 \%)$.

(E)- $N$-(2-(4-bromostyryl)phenyl)acetamide, 6e. Compound 5a (0.30 g, $1.15 \mathrm{mmol})$ was dissolved in $80 \mathrm{~mL}$ dry DMF. The solution was heated up to $120^{\circ} \mathrm{C}$ and refluxed under nitrogen for a few minutes. Palladium (II) acetate $(2.6 \mathrm{mg}, 0.0115 \mathrm{mmol})$ was added, followed by triethylamine $(0.7 \mathrm{~mL}$, $4.6 \mathrm{mmol})$ into the mixture. Compound $3 \mathrm{e}(0.2288 \mathrm{~g}, 1.25 \mathrm{mmol})$ was added into the reaction flask. The mixture was reflux under nitrogen until consumption of compound 5a (check via TLC). The reaction mixture was treated according to the general procedure. Purification of the crude product by column chromatography (dichloromethane/ethyl acetate, 97:3) afforded a yellow solid. Yield: $0.13 \mathrm{~g}(37 \%)$.

(E)- $N$-(2-(3,5-dimethoxystyryl)phenyl)acetamide, 6f. Compound 5a (1.02 g, $3.93 \mathrm{mmol})$ was dissolved in $10 \mathrm{~mL}$ dry DMF. The solution was heated up to $120{ }^{\circ} \mathrm{C}$ and refluxed under nitrogen for a few minutes. Palladium (II) acetate $(16.5 \mathrm{mg}, 0.0735 \mathrm{mmol})$ was added, followed by triethylamine $(1.94 \mathrm{~mL}, 13.9 \mathrm{mmol})$ into the mixture. Compound $\mathbf{3 f}(0.78 \mathrm{~g}, 4.77 \mathrm{mmol})$ was added into the reaction flask. The mixture was reflux under nitrogen until consumption of compound $\mathbf{5 a}$ (check via TLC). The reaction mixture was treated according to the general procedure. Purification of the crude product by column chromatography (hexane/ethyl acetate, 60:40) afforded an off-white solid. Yield: $0.52 \mathrm{~g}(45 \%)$.

(E)- $N$-(2-(2-methoxystyryl)phenyl)furan-2-carboxamide, 6g [15]. Compound $\mathbf{5 b}$ (1.51 g, $4.81 \mathrm{mmol})$ was dissolved in $25 \mathrm{~mL}$ dry DMF. The solution was heated up to $120{ }^{\circ} \mathrm{C}$ and refluxed under nitrogen for a few minutes. Palladium (II) acetate $(11.2 \mathrm{mg}, 0.0499 \mathrm{mmol})$ was added, followed by triethylamine 
(2.4 $\mathrm{mL}, 17.22 \mathrm{mmol})$ into the mixture. Compound $3 \mathrm{~g}(0.83 \mathrm{~g}, 6.16 \mathrm{mmol})$ was added into the reaction flask. The mixture was reflux under nitrogen until consumption of compound $\mathbf{5 b}$ (check via TLC). The reaction mixture was treated according to the general procedure. Purification of the crude product by column chromatography (hexane/ethyl acetate, 60:40) afforded a white solid. Yield: $0.75 \mathrm{~g}(49 \%)$.

(E)- $N$-(2-(3-methoxystyryl)phenyl)furan-2-carboxamide, $6 \mathbf{h}$ [15]. Compound $\mathbf{5 b}$ (0.44 g, $1.41 \mathrm{mmol})$ was dissolved in $20 \mathrm{~mL}$ dry DMF. The solution was heated up to $120{ }^{\circ} \mathrm{C}$ and refluxed under nitrogen for a few minutes. Palladium (II) acetate $(3.6 \mathrm{mg}, 0.0160 \mathrm{mmol}$ ) was added, followed by triethylamine $(0.8 \mathrm{~mL}, 5.74 \mathrm{mmol})$ into the mixture. Compound $\mathbf{3 h}(0.30 \mathrm{~g}, 2.24 \mathrm{mmol})$ was added into the reaction flask. The mixture was reflux under nitrogen until consumption of compound $\mathbf{5 b}$ (check via TLC). The reaction mixture was treated according to the general procedure. Purification of the crude product by column chromatography (hexane/ethyl acetate, 60:40) afforded a white solid. Yield: $0.15 \mathrm{~g} \mathrm{(33 \% ).}$

(E)- $N$-(2-(4-methoxystyryl)phenyl)furan-2-carboxamide, 6i [15]. Compound $\mathbf{5 b}$ (0.52 g, $1.65 \mathrm{mmol})$ was dissolved in $20 \mathrm{~mL}$ dry DMF. The solution was heated up to $120{ }^{\circ} \mathrm{C}$ and refluxed under nitrogen for a few minutes. Palladium (II) acetate $(3.6 \mathrm{mg}, 0.0160 \mathrm{mmol}$ ) was added, followed by triethylamine $(0.8 \mathrm{~mL}, 5.74 \mathrm{mmol})$ into the mixture. Compound $3 \mathbf{i}(0.32 \mathrm{~g}, 2.39 \mathrm{mmol})$ was added into the reaction flask. The mixture was reflux under nitrogen until consumption of compound $\mathbf{5 b}$ (check via TLC). The reaction mixture was treated according to the general procedure. Purification of the crude product by column chromatography (hexane/ethyl acetate, 60:40) afforded a white solid. Yield: $0.19 \mathrm{~g}(36 \%)$.

(E)- $N$-(2-(3,4-dimethoxystyryl)phenyl)furan-2-carboxamide, 6j [15]. Compound 5b (0.57 g, $1.83 \mathrm{mmol}$ ) was dissolved in $25 \mathrm{~mL}$ dry DMF. The solution was heated up to $120{ }^{\circ} \mathrm{C}$ and refluxed under nitrogen for a few minutes. Palladium (II) acetate $(5.2 \mathrm{mg}, 0.0232 \mathrm{mmol})$ was added, followed by triethylamine $(1.2 \mathrm{~mL}, 8.61 \mathrm{mmol})$ into the mixture. Compound $\mathbf{3 j}(0.35 \mathrm{~g}, 2.14 \mathrm{mmol})$ was added into the reaction flask. The mixture was reflux under nitrogen until consumption of compound $\mathbf{5 b}$ (check via TLC). The reaction mixture was treated according to the general procedure. Purification of the crude product by column chromatography (hexane/ethyl acetate, 60:40) afforded a white solid. Yield: $0.10 \mathrm{~g}(16 \%)$.

(E)-N-(2-(3,5-dimethoxystyryl)phenyl)furan-2-carboxamide, 6k [15]. Compound 5b (0.57 g, $1.83 \mathrm{mmol}$ ) was dissolved in $25 \mathrm{~mL}$ dry DMF. The solution was heated up to $120{ }^{\circ} \mathrm{C}$ and refluxed under nitrogen for a few minutes. Palladium (II) acetate $(5.2 \mathrm{mg}, 0.0232 \mathrm{mmol})$ was added, followed by triethylamine $(1.2 \mathrm{~mL}, 8.61 \mathrm{mmol})$ into the mixture. Compound $\mathbf{3 f}(0.35 \mathrm{~g}, 2.14 \mathrm{mmol})$ was added into the reaction flask. The mixture was reflux under nitrogen until consumption of compound $\mathbf{5 b}$ (check via TLC). The reaction mixture was treated according to the general procedure. Purification of the crude product by column chromatography (hexane/ethyl acetate, 60:40) afforded a white solid. Yield: $0.10 \mathrm{~g}(17 \%)$.

(E)-N-(2-(2-(biphenyl-4-yl)vinyl)phenyl)furan-2-carboxamide, $6 \mathbf{l}$ [15]. Compound 5b (0.37 g, $1.18 \mathrm{mmol}$ ) was dissolved in $20 \mathrm{~mL}$ dry DMF. The solution was heated up to $120{ }^{\circ} \mathrm{C}$ and refluxed under nitrogen for a few minutes. Palladium (II) acetate $(3.2 \mathrm{mg}, 0.0143 \mathrm{mmol})$ was added, followed by triethylamine $(0.7 \mathrm{~mL}, 4.66 \mathrm{mmol})$ into the mixture. Compound $3 \mathbf{k}(0.20 \mathrm{~g}, 1.21 \mathrm{mmol})$ was added into the reaction flask. The mixture was reflux under nitrogen until consumption of compound $\mathbf{5 b}$ (check via TLC). The reaction mixture was treated according to the general procedure. Purification of 
the crude product by column chromatography (hexane/ethyl acetate, 90:10) afforded a yellowish solid. Yield: $0.04 \mathrm{~g}(9 \%)$.

(E)-N-(2-(2-([1,1'-biphenyl]-4-yl)vinyl)phenyl)benzamide, $6 \mathbf{m} \quad$ [15]. Compound 5c $(0.17 \mathrm{~g}$, $0.5106 \mathrm{mmol}$ ) was dissolved in $20 \mathrm{~mL}$ dry DMF. The solution was heated up to $120{ }^{\circ} \mathrm{C}$ and refluxed under nitrogen for a few minutes. Palladium (II) acetate $(2.5 \mathrm{mg}, 0.0111 \mathrm{mmol})$ was added, followed by triethylamine $(1.0 \mathrm{~mL}, 7.17 \mathrm{mmol})$ into the mixture. Compound $3 \mathbf{k}(0.10 \mathrm{~g}, 0.5570 \mathrm{mmol})$ was added into the reaction flask. The mixture was reflux under nitrogen until consumption of compound 5c (check via TLC). The reaction mixture was treated according to the general procedure. Purification of the crude product by column chromatography (hexane/ethyl acetate, 90:10) afforded a white solid. Yield: $0.06 \mathrm{~g}(31 \%)$.

(E)-N-(2-(3,4-dimethoxystyryl)phenyl)benzamide, 6n [15]. Compound 5c (0.51 g, $1.58 \mathrm{mmol})$ was dissolved in $20 \mathrm{~mL}$ dry DMF. The solution was heated up to $120{ }^{\circ} \mathrm{C}$ and refluxed under nitrogen for a few minutes. Palladium (II) acetate $(3.5 \mathrm{mg}, 0.0156 \mathrm{mmol})$ was added, followed by triethylamine $(0.8 \mathrm{~mL}, 5.74 \mathrm{mmol})$ into the mixture. Compound $\mathbf{3 j}(0.37 \mathrm{~g}, 2.24 \mathrm{mmol})$ was added into the reaction flask. The mixture was reflux under nitrogen until consumption of compound $\mathbf{5 c}$ (check via TLC). The reaction mixture was treated according to the general procedure. Purification of the crude product by column chromatography (hexane/ethyl acetate, 80:20) afforded a white solid. Yield: $0.10 \mathrm{~g}(18 \%)$.

(E)-N-(2-(4-methoxystyryl)phenyl)benzamide, 6o. Compound 5c $(0.51 \mathrm{~g}, 1.58 \mathrm{mmol})$ was dissolved in $20 \mathrm{~mL}$ dry DMF. The solution was heated up to $120{ }^{\circ} \mathrm{C}$ and refluxed under nitrogen for a few minutes. Palladium (II) acetate $(3.5 \mathrm{mg}, 0.0156 \mathrm{mmol})$ was added, followed by triethylamine $(0.8 \mathrm{~mL}, 5.74 \mathrm{mmol})$ into the mixture. Compound $\mathbf{3 i}(0.32 \mathrm{~g}, 2.39 \mathrm{mmol})$ was added into the reaction flask. The mixture was reflux under nitrogen until consumption of compound $\mathbf{5 c}$ (check via TLC). The reaction mixture was treated according to the general procedure. Purification of the crude product by column chromatography (hexane/ethyl acetate, 80:20) afforded a white solid. Yield: $0.15 \mathrm{~g} \mathrm{(28 \% ).}$

(E)-N-(2-(3,4-dimethoxystyryl)phenyl)cyclohexanecarboxamide, 6p [15]. Compound 5d (0.21 g, $0.63 \mathrm{mmol}$ ) was dissolved in $20 \mathrm{~mL}$ dry DMF. The solution was heated up to $120{ }^{\circ} \mathrm{C}$ and refluxed under nitrogen for a few minutes. Palladium (II) acetate $(2.1 \mathrm{mg}, 0.0094 \mathrm{mmol})$ was added, followed by triethylamine $(0.5 \mathrm{~mL}, 3.59 \mathrm{mmol})$ into the mixture. Compound $\mathbf{3 j}(0.15 \mathrm{~g}, 0.93 \mathrm{mmol})$ was added into the reaction flask. The mixture was reflux under nitrogen until consumption of compound $\mathbf{5 d}$ (check via TLC). The reaction mixture was treated according to the general procedure. Purification of the crude product by column chromatography (hexane/ethyl acetate, 80:20) afforded a white solid. Yield: $0.07 \mathrm{~g}(31 \%)$.

(E)- $N$-(2-(3,4-dimethoxystyryl)phenyl)isobutyramide, 6q [15]. Compound 5e (1.49 g, 5.16 mmol) was dissolved in $25 \mathrm{~mL}$ dry DMF. The solution was heated up to $120{ }^{\circ} \mathrm{C}$ and refluxed under nitrogen for a few minutes. Palladium (II) acetate $(11.9 \mathrm{mg}, 0.053 \mathrm{mmol})$ was added, followed by triethylamine ( $2.8 \mathrm{~mL}, 20.09 \mathrm{mmol})$ into the mixture. Compound $\mathbf{3 j}$ (1.02 $\mathrm{g}, 6.23 \mathrm{mmol})$ was added into the reaction flask. The mixture was reflux under nitrogen until consumption of compound $\mathbf{5 e}$ (check via TLC). The reaction mixture was treated according to the general procedure. Purification of the crude product by column chromatography (hexane/ethyl acetate, 80:20) afforded an off-white solid. Yield: 0.4505 g (27\%). 
(E)- $N$-(2-(4-methoxystyryl)phenyl)isobutyramide, 6r. Compound 5e $(0.31 \mathrm{~g}, 1.09 \mathrm{mmol})$ was dissolved in $20 \mathrm{~mL}$ dry DMF. The solution was heated up to $120{ }^{\circ} \mathrm{C}$ and refluxed under nitrogen for a few minutes. Palladium (II) acetate $(2.4 \mathrm{mg}, 0.0011 \mathrm{mmol})$ was added, followed by triethylamine $(0.6 \mathrm{~mL}, 4.30 \mathrm{mmol})$ into the mixture. Compound $3 \mathbf{i}(0.22 \mathrm{~g}, 1.37 \mathrm{mmol})$ was added into the reaction flask. The mixture was reflux under nitrogen until consumption of compound $\mathbf{5 e}$ (check via TLC). The reaction mixture was treated according to the general procedure. Purification of the crude product by column chromatography (hexane/ethyl acetate, 80:20) afforded an off-white solid. Yield: $0.05 \mathrm{~g}$ (14\%).

(E)-N-(2-(3,4-dimethoxystyryl)phenyl)butyramide, 6s [15]. Compound 5f (0.31 g, $1.09 \mathrm{mmol})$ was dissolved in $20 \mathrm{~mL}$ dry DMF. The solution was heated up to $120{ }^{\circ} \mathrm{C}$ and refluxed under nitrogen for a few minutes. Palladium (II) acetate $(2.4 \mathrm{mg}, 0.0011 \mathrm{mmol})$ was added, followed by triethylamine $(0.6 \mathrm{~mL}, 4.30 \mathrm{mmol})$ into the mixture. Compound $\mathbf{3 j}(0.22 \mathrm{~g}, 1.37 \mathrm{mmol})$ was added into the reaction flask. The mixture was reflux under nitrogen until consumption of compound $\mathbf{5 f}$ (check via TLC). The reaction mixture was treated according to the general procedure. Purification of the crude product by column chromatography (hexane/ethyl acetate, 80:20) afforded an off-white solid. Yield: $0.05 \mathrm{~g}$ (15\%).

\section{References}

1. Simoni, D.; Invidiata, F.P.; Eleopra, M.; Marchetti, P.; Rondanin, R.; Baruchello, R.; Grisolia, G.; Tripathi, A.; Kellogg, G.E.; Durrant, D.; et al. Design, synthesis and biological evaluation of novel stilbene-based antitumor agents. Biorg. Med. Chem. 2009, 17, 512-522.

2. Belluti, F.; Fontana, G.; Dal Bo, L.; Carenini, N.; Giommarelli, C.; Zunino, F. Design, synthesis and anticancer activities of stilbene-coumarin hybrid compounds: Identification of novel proapoptotic agents. Biorg. Med. Chem. 2010, 18, 3543-3550.

3. Sanoh, S.; Kitamura, S.; Sugihara, K.; Fujimoto, N.; Ohta, S. Estrogenic activity of stilbene derivatives. J. Health Sci. 2003, 49, 359-367.

4. Soleas, G.J.; Diamandis, E.P.; Goldberg, D.M. Resveratrol: A molecule whose time has come? And gone? Clin. Biochem. 1997, 30, 91-113.

5. Gusman, J.; Malonne, H.; Atassi, G. A reappraisal of the potential chemopreventive and chemotherapeutic properties of resveratrol. Carcinogenesis 2001, 22, 1111-1117.

6. Takaoka, M. The phenolic substances of white hellebore (Veratrum grandiflorum Loes. Fil.) resveratrol. Nippon Kagaku Kaishi 1939, 60, 1090-1100.

7. Albert, S.; Horbach, R.; Deising, H.B.; Siewert, B.; Csuk, R. Synthesis and antimicrobial activity of (E) stilbene derivatives. Biorg. Med. Chem. 2011, 19, 5155-5166.

8. Park, S.J.; Ahmad, F.; Philp, A.; Baar, K.; Williams, T.; Luo, H.; Ke, H.; Rehmann, H.; Taussig, R.; Brown, A.L.; et al. Resveratrol ameliorates aging-related metabolic phenotypes by inhibiting cAMP phosphodiesterases. Cell 2012, 148, 421-433.

9. Arichi, H.; Kimura, Y.; Okuda, H.; Baba, K.; Kozawa, M.; Arichi, S. Effects of stilbene components of the roots of Polygonum cuspidatum Sieb. et Zucc. on lipid metabolism. Chem. Pharm. Bull. 1982, 30, 1766-1770.

10. Li, H.; Xia, N.; Forstermann, U. Cardiovascular effects and molecular targets of resveratrol. Nitric Oxide 2012, 26, 102-110. 
11. Minutolo, F.; Sala, G.; Bagnacani, A.; Bertini, S.; Carboni, I.; Placanica, G.; Prota, G.; Rapposelli, S.; Sacchi, N.; Macchia, M.; et al. Synthesis of a resveratrol analogue with high ceramide-mediated proapoptotic activity on human vreast cancer cells. J. Med. Chem. 2005, 48, 6783-6786.

12. Maya, A.B.; Perez-Melero, C.; Mateo, C.; Alonso, D.; Fernandez, J.L.; Gajate, C.; Mollinedo, F.; Pelaez, R.; Caballero, E.; Medarde, M. Further naphthylcombretastatins. An investigation on the role of the naphthalene moiety. J. Med. Chem. 2004, 48, 556-568.

13. Chen, L.; Zhang, Y.; Sun, X.; Li, H.; LeSage, G.; Javer, A.; Zhang, X.; Wei, X.; Jiang, Y.; Yin, D. Synthetic resveratrol aliphatic acid inhibits TLR2-mediated apoptosis and an involvement of Akt/GSK3 $\beta$ pathway. Biorg. Med. Chem. 2009, 17, 4378-4382.

14. Yang, L.M.; Lin, S.J.; Hsu, F.L.; Yang, T.H. Antitumor agents. Part 3: Synthesis and cytotoxicity of new trans-Stilbene benzenesulfonamide derivatives. Bioorg. Med. Chem. Lett. 2002, 12, 1013-1015.

15. Kee, C.H.; Ariffin, A.; Awang, K.; Takeya, K.; Morita, H.; Hussain, S.I.; Chan, K.M.; Wood, P.J.; Threadgill, M.D.; Lim, C.G.; et al. Challenges associated with the synthesis of unusual $o$-carboxamido stilbenes by the Heck protocol: Intriguing substituent effects, their toxicological and chemopreventive implications. Org. Biomol. Chem. 2010, 8, 5646-5660.

16. Thomas, N.F.; Velu, S.S.; Weber, J.-F.F.; Lee, K.C.; Hadi, A.H.A.; Richomme, P.; Rondeau, D.; Noorbatcha, I.; Awang, K. A tandem highly stereoselective FeCl3-promoted synthesis of a bisindoline: Synthetic utility of radical cations in heterocyclic construction. Tetrahedron 2004, 60, 11733-11742.

17. Ahmad, K.; Thomas, N.F.; Mukhtar, M.R.; Noorbatcha, I.; Faizal Weber, J.F.; Nafiah, M.A.; Velu, S.S.; Takeya, K.; Morita, H.; Lim, C.G.; et al. A $\mathrm{FeCl}_{3}$-promoted highly atropodiastereoselective cascade reaction: Synthetic utility of radical cations in indolostilbene construction. Tetrahedron 2009, 65, 1504-1516.

18. Ladziata, U.; Koposov, A.Y.; Lo, K.Y.; Willging, J.; Nemykin, V.N.; Zhdankin, V.V. Synthesis, structure and chemoselective reactivity of $N$-(2-iodylphenyl)acylamides: Hypervalent iodine reagents bearing a pseudo-six-membered ring scaffold. Angew. Chem. Int. Ed. 2005, 44, 7127-7131.

19. Schneider, Y.; Vincent, F.; Duranton, B.; Badolo, L.; Gosse, F.; Bergmann, C.; Seiler, N.; Raul, F. Anti-proliferative effect of resveratrol, a natural component of grapes and wine, on human colonic cancer cells. Cancer Lett. 2000, 158, 85-91.

20. Sgambato, A.; Ardito, R.; Faraglia, B.; Boninsegna, A.; Wolf, F.I.; Cittadini, A. Resveratrol, a natural phenolic compound, inhibits cell proliferation and prevents oxidative DNA damage. Mutat. Res. 2001, 496, 171-180.

21. Saiko, P.; Szakmary, A.; Jaeger, W.; Szekeres, T. Resveratrol and its analogs: Defense against cancer, coronary disease and neurodegenerative maladies or just a fad? Mutat. Res. 2008, 658, 68-94. 
22. Boele, M.D.; van Strijdonck, G.P.; de Vries, A.H.; Kamer, P.C.; de Vries, J.G.; van Leeuwen, P.W. Selective Pd-catalyzed oxidative coupling of anilides with olefins through $\mathrm{C}-\mathrm{H}$ bond activation at room temperature. J. Am. Chem. Soc. 2002, 124, 1586-1587.

23. Kee, C.H.; Thomas, N.F.; Ariffin, A.; Awang, K.; Ng, S.W. (E)-N-[2-(Biphenyl-4ylvinyl)phenyl]furan-2-carboxamide. Acta Crystallogr. 2008, 64, o2210.

24. Boyd, M.R.; Paull, K.D. Some practical considerations and applications of the national cancer institute in vitro anticancer drug discovery screen. Drug Dev. Res. 1995, 34, 91-109.

(C) 2013 by the authors; licensee MDPI, Basel, Switzerland. This article is an open access article distributed under the terms and conditions of the Creative Commons Attribution license (http://creativecommons.org/licenses/by/3.0/). 